\title{
Octanuclear Ni4Ln 4 Coordination Aggregates from Schiff Base Anion Supports and Connecting of Two Ni2 Ln2 Cubes: Syntheses, Structures, and Magnetic Properties
}

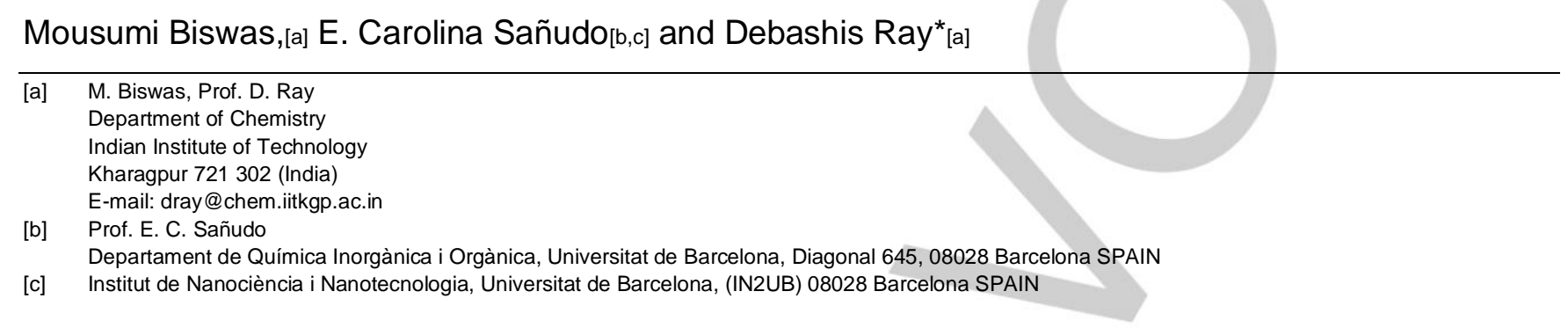

\begin{abstract}
A family of $3 d-4 f$ aggregates have been reported through guiding the dual coordination modes of ligand anion (HL-) and in situ generated ancillary bridge driven self-assembly coordination responses toward two different types of metal ions. Reactions of lanthanide(III) nitrate ( $\mathrm{Ln}=\mathrm{Gd}, \mathrm{Tb}, \mathrm{Dy}, \mathrm{Ho}$ and $\mathrm{Yb})$, nickel(II) acetate and phenol-based ditopic ligand anion of 2-[\{(2hydroxypropyl)imino\}methyl]-6-methoxyphenol $\left(\mathrm{H}_{2} \mathrm{~L}\right)$ in $\mathrm{MeCN}-\mathrm{MeOH}$ (3:1) mixture and $\mathrm{LiOH}$ provided five new octanuclear $\mathrm{Ni}-4 f$ coordination aggregates from two $\mathrm{Ni}_{2} \mathrm{Ln}_{2}$ cubanes. Single-crystal $X$ ray diffraction analysis reveals that all the members of the family are isostructural, with the central core formed from the coupling of two distorted $\left[\mathrm{Ni}_{2} \mathrm{Ln}_{2} \mathrm{O}_{4}\right]$ heterometallic cubanes $\left[\mathrm{Ni}_{2} \mathrm{Ln}_{2}(\mathrm{HL})_{2}\left(\mu_{3}-\right.\right.$ $\left.\mathrm{OH})_{2}(\mathrm{OH})(\mathrm{OAc})_{4}\right]_{+}(\mathrm{Ln}=\mathrm{Gd}(\mathbf{1}), \mathrm{Tb}(\mathbf{2})$, Dy (3), Ho (4) and $\mathrm{Yb}(\mathbf{5}))$. Higher coordination demand of $4 f$ ions induced the coupling of the two cubes by $(\mathrm{OH})(\mathrm{OAc})_{2}$ bridges. Variable temperature magnetic study reveals weak coupling between the $\mathrm{Ni}_{2}$ and $\mathrm{Ln}_{3+}$ ions. For the $\mathrm{Tb}(2)$ and Dy (3) analogs, the compounds are SMMs, whereas the Gd (1) analogue is not an SMM. The observation revealed thus that the anisotropy of the $\mathrm{Ln}_{3+}$ ions is central to display the SMM behavior within this structurally intriguing family of compounds.
\end{abstract}

\section{Introduction}

Ligand anion bound multinuclear coordination aggregates of two similar or different types of metal ions form an exclusive class of assemblies, many of which can have visually pleasing molecular designs. Their exciting physical and chemical properties arise primarily from the electronic and/or magnetic interplay between the constituent metal ions of varying numbers trapped by the ligand anions. In recent years the field of molecular magnetism have seen an enormous progress in laboratory-level synthesis following the observation of nanosized $\mathrm{Mn}_{12}$ aggregate exhibiting a bistable magnetic ground state and magnetic hysteresis. 1 The gram-scale synthesis of the compound basically laid the foundation for research in improving and perfecting control over the magnetic relaxation of single molecule magnets (SMMs). Past two decades have also witnessed the enormous growth in the synthesis and magnetic characterization of coordination aggregates (CAs) based on only $4 f$ ions and $3 d-4 f$ ions together for exciting molecular structures and potential to exhibit SMM behavior. Such studies lead to the consideration that in such CAs a high spin ground state (S) and a negative magnetic anisotropy (D) must be present to attain high anisotropic energy barriers ( $\left.U_{\text {eff }}\right)$ for the reversal of magnetization.2 Such molecule-based nanomagnets thus have received considerable interest because they present themselves as discrete models for understanding the quantum phenomenon and varied applications in the fields of quantum computing,3 spintronics, 4 and high density information storage.5 Till to date many such SMMs bearing $3 d, 3 d-4 f$, or $4 f$ ions have been obtained with the aim of increasing the blocking temperature $\left(T_{B}\right) .6-8$ Most of the $4 f$ ion based systems have better performance, compared to pure $3 d$-based SMMs, due to strong magnetic anisotropy of $4 \mathrm{fions}$. Which arises from the combination of large magnetic moments, strong spin-orbit coupling and crystal-field effects.9

Only recently $4 \mathrm{f}$ ion bearing mononuclear SMMs have reached an operational temperature above $77 \mathrm{~K} .10$ However, $4 f$ ions show weak magnetic coupling when present at the adjoining coordination sites and bridged by one of more donor atoms. ${ }_{11}$ As a result considerable synthetic challenges have been taken for the construction of new genre of $3 d-4 f$ coordination aggregates which can increase the strength of magnetic coupling and suppression of quantum tunneling of magnetization (QTM).12 Depending upon the design characteristics to convey efficiently the coupling effect of different paramagnetic centers in SMMs, it has been observed that the selected multitopic ligands do participate efficiently in trapping multiple number of $3 d$ and $4 f$ ions to grow multinuclear CAs. Choice and efficacy of these ligands 
depend on the nature of coordination sites and its back bone to bring the two types of metal ions in close proximity. Recent synthesis, structure determination and theoretical modeling studies have shown that the height of the magnetization relaxation barrier depends on both single-ion anisotropy and 3d-4f magnetic exchange interactions. As a result, when the $3 d-4 f$ magnetic exchange coupling is adequate, the exchange-coupled levels are well separated (avoiding mixing of low-lying excited states in the ground state) and suppression of QTM is observed. This results in the observation of large energy barriers, hysteresis loops and relaxation. Thus, magnetic interactions between the $3 d$ and $4 f$ ions bound to a new ligand anion platform can be effectively utilized to slow down the magnetic relaxation process.

Phenol-based Schiff base derivatives having one or more alcohol arms are versatile ligands for the synthesis of variety of $3 d-4 f$ coordination compounds. Such ligand anions are well suited to grow $3 d-4 f$ aggregates, wherein the imine donor site can bind $3 d$ ion and the phenolate ion bridge the $3 d$ and $4 f$ ions. Combination of these donor sites along with alcohol ends can bind several $3 d$ and $4 f$ ions to exhibit the magnetism arising from the contributions of large local magnetic anisotropy and favorable magnetic exchange coupling.13 Multimetallic complexes containing nickel(II) and lanthanide(III) ions are of interest because of the dominant ferromagnetic exchange interactions observed frequently.14 Up till now, many Ni-Ln based complexes of varying nuclearity have shown magnetic behavior necessary for magnetic refrigeration.15 For some time we have been working in controlling the assembly of multiple $3 d$ ions in CAs to study their spectroscopic, magnetic, catalytic and functional properties.16 Herein we report a new family of $\mathrm{Ni}_{4} \mathrm{Ln}_{4}$ complexes $(\mathrm{Ln}=\mathrm{Gd}, \mathbf{1}$; Tb, 2; Dy, 3; Ho, 4; Yb, 5) assembled from two symmetric Ni2Ln2 cubes, using 2-[\{(2-hydroxypropyl)imino $\}$ methyl]-6methoxyphenol $\left(\mathrm{H}_{2} \mathrm{~L}\right)$ ligand (Chart 1). Initial growth of heterometallic and distorted $\mathrm{Ni}_{2} \mathrm{Ln}_{2}$ cubes are achieved on $\mu_{3}$ supports from ligand phenoxido and ancillary hydroxido groups.17 Demand for higher coordination number of the lanthanide(III) ions and preference for bigger coordination spheres permitted the final connections of two such cubes around the LnIII centers by four AcO- and two HO- bridges (Chart 2). The synthesis, characterization and magnetic behavior of a new family of $\mathrm{Ni}-\mathrm{Ln}$ aggregates are discussed.

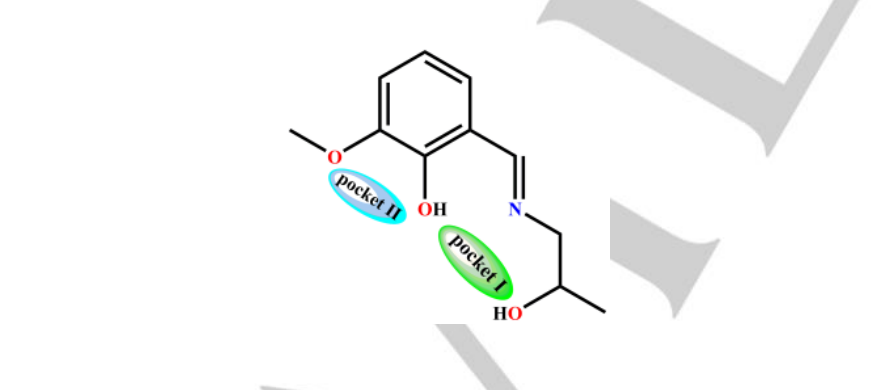

Chart 1. $\mathrm{H}_{2} \mathrm{~L}$ used in this work.
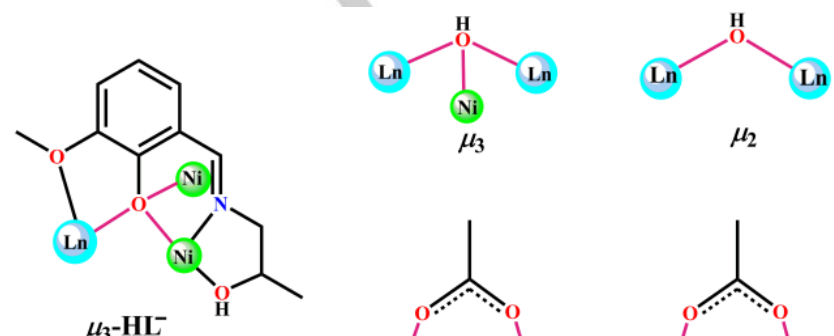

$\mu_{3}-\mathrm{HL}^{-}$
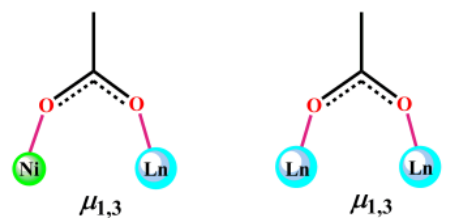

Chart 2. Coordination modes of $\mathrm{HL}_{-}, \mathrm{OH}-$ and $\mathrm{OAC}$ - observed in this work.

\section{Results and Discussion}

Synthetic Aspects. The formation of complexes 1-5 resulted from sequential reaction of $\mathrm{Ln}\left(\mathrm{NO}_{3}\right)_{3} \cdot \mathrm{nH}_{2} \mathrm{O}(\mathrm{n}=6$ or 5$)(\mathrm{Ln}=\mathrm{Gd}$, $\mathrm{Tb}, \mathrm{Dy}, \mathrm{Ho}, \mathrm{Yb})$ and $\mathrm{Ni}(\mathrm{OAc})_{2} \cdot 4 \mathrm{H}_{2} \mathrm{O}$ with $\mathrm{H}_{2} \mathrm{~L}(1: 1: 1$ molar ratio) in $\mathrm{MeCN}-\mathrm{MeOH}$ medium in presence of $\mathrm{LiOH}$, under standard laboratory and room temperature conditions.

$\mathrm{H}_{2} \mathrm{~L}$ was obtained from a Schiff base condensation reaction of ovanillin and 1-amino propan-2-ol. Heterometallic (3d-4f) complex forming ability of the anion of $\mathrm{H}_{2} \mathrm{~L}$ was explored during the reactions with lanthanide(III) and nickel(II) ions in mixed solvent medium followed by room temperature evaporation. Direct crystallizations from the final reaction solution afforded octanuclear complexes 1-5, suitable for X-ray structure analysis. (eq 1)

\section{$4 \mathrm{H}_{2} \mathrm{~L}+4 \mathrm{Ln}\left(\mathrm{NO}_{3}\right)_{3} \cdot(5-6) \mathrm{H}_{2} \mathrm{O}+4 \mathrm{Ni}\left(\mathrm{CH}_{3} \mathrm{COO}\right)_{2} \cdot 4 \mathrm{H}_{2} \mathrm{O}+8 \mathrm{LiOH}$ $\stackrel{\mathrm{MeCN}: \mathrm{MeOH}}{\longrightarrow}$$$
\text { (3:1,v/v) }
$$

$\left[\mathrm{Ni}_{4} \mathrm{Ln}_{4}(\mu-\mathrm{HL})_{4}\left(\mu_{3}-\mathrm{OH}\right)_{4}(\mu-\mathrm{OH})_{2}\left(\mu-\mathrm{OOCCH}_{3}\right)_{8}\right] \cdot\left(\mathrm{NO}_{3}\right)_{2} \cdot(12-24) \mathrm{H}_{2} \mathrm{O}$ $+8 \mathrm{Li}_{+}+10 \mathrm{NO}_{3-+}(38-54) \mathrm{H}_{2} \mathrm{O} \quad \ldots \ldots \ldots . .(1)$

In situ generated HO- ions were judiciously utilized for the hydrolytic aggregation of eight metal ions of two discrete types and supported by four $\mu-\mathrm{HL}$ - ions. Nickel(II) salt derived all the $\mathrm{CH}_{3} \mathrm{CO}_{2}$ - ion were quantitatively consumed for the intra- and intercubic connections within the molecular aggregates. No externally added $\mathrm{CH}_{3} \mathrm{CO}_{2} \mathrm{Na}$ salt was necessary for the eight $\mathrm{CH}_{3} \mathrm{CO}_{2}$ ions utilized in 1-5.

Initial characterizations of the CAs in the solid state were performed from the use of FT-IR (ATR technique) spectroscopy and PXRD studies. These data are useful for the quantification and characterization of the powder samples obtained after each synthesis. The PXRD patterns of the synthesized samples are in good agreement with the simulated ones from the single-crystal XRD data for each complex. Earlier Mutka et al. and Liu et al have shown that corresponding phenol-based ligands are useful with nickel salts to provide $\mathrm{Ni}_{4} \mathrm{O}_{4}$ cube structures.18a,18b Thereafter the ligands with modified side arms are further explored by many groups for $3 d-4 f$ aggregate formation. The anionic form of 2(benzothiazol-2-ylhydrazonomethyl)-6-methoxyphenol $\left(\mathrm{H}_{2} \mathrm{~L}\right)$ on reaction with $\mathrm{Ni}(\mathrm{OAc})_{2} \cdot 4 \mathrm{H}_{2} \mathrm{O}$ and $\mathrm{Ln}\left(\mathrm{ClO}_{4}\right)_{3} \cdot 6 \mathrm{H}_{2} \mathrm{O}$ provides $\left[\mathrm{Ni}_{2} \mathrm{Ln}_{2}\left(\mu_{3}-\mathrm{OH}\right)_{2}(\mathrm{OH})(\mathrm{OAc})_{4}(\mathrm{HL})_{2}(\mathrm{MeOH})_{3}\right]\left(\mathrm{ClO}_{4}\right) \cdot 3 \mathrm{MeOH} \quad(\mathrm{Ln}=$ $\mathrm{Dy}, \mathrm{Tb}$ and $\mathrm{Gd}$ ) with several terminally bound $\mathrm{HO}_{-}, \mathrm{AcO}$ - and $\mathrm{MeOH}$ groups as reported by Liu et al.19 Tong et al. shown that room temperature single pot reaction of o-vanillin, 2hydrazinopyridine, $\mathrm{Ni}\left(\mathrm{ClO}_{4}\right)_{2} \cdot 6 \mathrm{H}_{2} \mathrm{O}$ and $\mathrm{Ln}(\mathrm{OAc})_{3} \cdot 6 \mathrm{H}_{2} \mathrm{O}$ in $\mathrm{MeOH}$ EtOH gave $\left[\mathrm{Ni}_{2} \mathrm{Ln}_{2}\left(\mu_{3}-\mathrm{OH}\right)_{2}(\mathrm{~L})_{2}(\mathrm{OAc})_{4}\left(\mathrm{H}_{2} \mathrm{O}\right)_{3.5}\right]\left(\mathrm{ClO}_{4}\right)_{2} \cdot 3 \mathrm{H}_{2} \mathrm{O}$ having terminal coordination of $\mathrm{AcO}_{-}, \mathrm{EtOH}$ and $\mathrm{H}_{2} \mathrm{O}$ inhibiting further aggregation.17b $\mathrm{Hor}$ et al. reported a $\mathrm{Ni}_{3} \mathrm{Ln}$ type cubane type complex from the use of 2-(hydroxymethyl)pyridine as ligand, $\mathrm{Ni}(\mathrm{OAc})_{2} \cdot 4 \mathrm{H}_{2} \mathrm{O}$ and $\mathrm{Ln}(\mathrm{OAc})_{3}$ in THF medium (Scheme 1).20 In our work we are fortunate enough to obtain further aggregation 
from two initially formed $\mathrm{Ni}_{2} \mathrm{Ln}_{2}$ cubes and new bridging connections of four $\mathrm{AcO}$ - and two $\mathrm{HO}$ - groups. Thus, the nature of ligand system and the choice of synthetic protocol are deterministic for the new routes for octanulcear $3 d-4 f$ coordination aggregates.

To identify the structural integrity of the aggregates in solution, HRMS analysis was used in $\mathrm{MeOH}$ solutions. The mass spectra

(a)

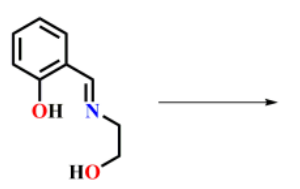

(b)<smiles>COc1cccc(C=CCCO)c1O</smiles>

(c)

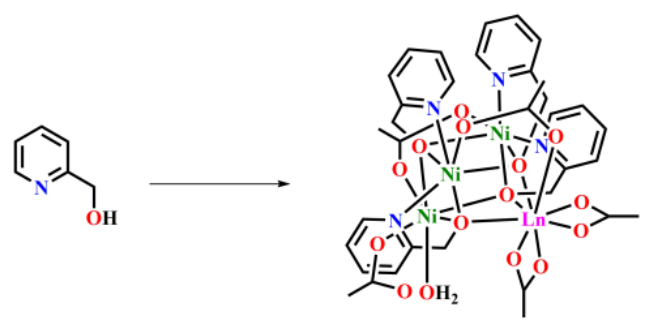

(d)

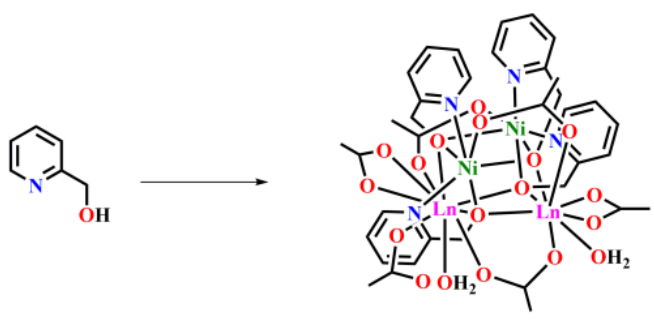

(e)<smiles>CC[Ge]</smiles>

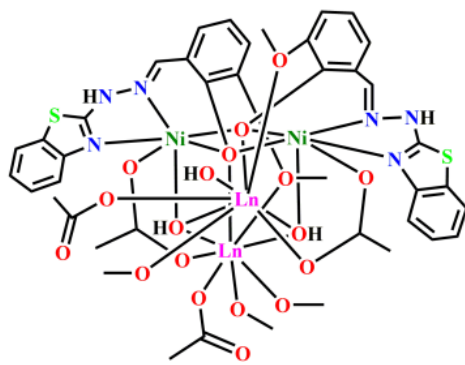

(f)

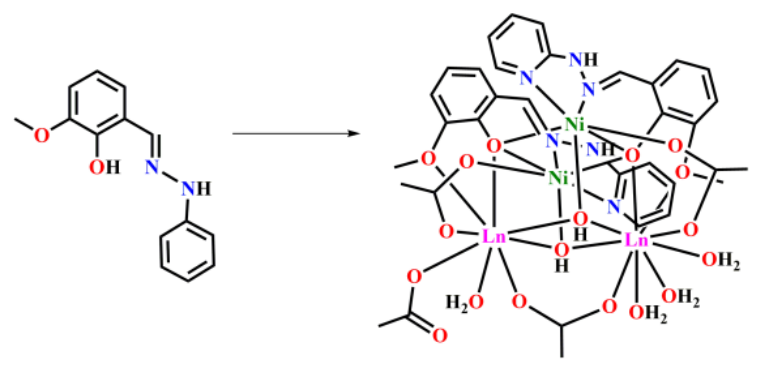

Scheme 1. Some previously known examples of cubes by allied ligands with $\mathrm{Ni}$ only (a), 18a (b) $18 \mathrm{~b}$ and Ni-4f metals (c),20 (d) $17 \mathrm{a},(\mathrm{e}) 19$ and (f) 17b

identify a mononuclear ligand anion bound $\mathrm{Ni}_{2}$ fragment $[\mathrm{Ni}(\mathrm{HL})]+$ at a $\mathrm{m} / \mathrm{z}$ value of 266.05 (calcd. 266.03 for $\mathrm{C}_{11} \mathrm{H}_{14} \mathrm{NNNO}_{3}$ ) and two prominent peaks at $\mathrm{m} / \mathrm{z}$ of 475.17 (calcd. 475.13 for $\mathrm{C}_{22} \mathrm{H}_{29} \mathrm{~N}_{2} \mathrm{NiO}_{6}$ ) and 531.09 (calcd. 531.05 for $\mathrm{C}_{22} \mathrm{H}_{27} \mathrm{~N}_{2} \mathrm{Ni}_{2} \mathrm{O}_{6}$ ) which were assignable to the fragments of $\left[\mathrm{Ni}(\mathrm{HL})\left(\mathrm{H}_{2} \mathrm{~L}\right)\right]_{+}$and $\left[\mathrm{Ni}_{2}(\mathrm{~L})(\mathrm{HL})\right]_{+}$respectively. (Figure S7 and S8) However, we are unable to detect any peak corresponding to lanthanide bound fragments.

\section{Initial Solid State Characterizations}

The solid products obtained from the above reactions as crystalline material were first checked by recording their ATR-FTIR signatures, DRS bands and PXRD patterns.

\section{FT-IR spectra}

The FT-IR spectra of complexes $\mathbf{1 - 5}$ are similar, showing the representative $\overline{\boldsymbol{\nu}}_{\mathrm{C}=\mathrm{N}}$ stretching frequency in $1651-1655 \mathrm{~cm}-1$ range for positively charged metal ion bound imine groups. For the free $\mathrm{H}_{2} \mathrm{~L}$ the corresponding $\widetilde{\boldsymbol{v}}_{\mathrm{C}=\mathrm{N}}$ stretching vibration is observed at $1631 \mathrm{~cm}_{-1}$ (Figure $\mathrm{S} 1 \mathrm{in} \mathrm{SI}$ ). The presence of bridging HO- groups and lattice water molecules are revealed by one broad band within 3415-3362 cm-1. For the complexes 1-5, the asymmetric carboxylate stretching vibrations, $\widetilde{\mathbf{v}}_{\mathrm{as}(\mathrm{COO}) \text {, are found }}$ at $1565,1567,1569,1567$ and $1560 \mathrm{~cm}_{-1}$, while the symmetric ones for $\tilde{\boldsymbol{v}}_{\mathrm{s}(\mathrm{COO})}$ appear at $1411,1417,1424,1416$ and $1411 \mathrm{~cm}-1$,

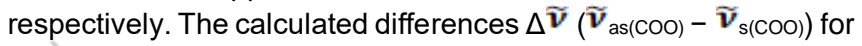
each complex remain within 149-154 cm-1, confirming the

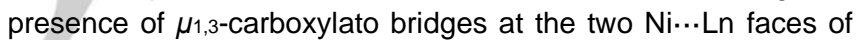
each cube and two other for connecting two such $\mathrm{Ni}_{2} \mathrm{Ln} 2$ cubes from the LnIII corners of the cubes.

\section{Powder X-ray diffraction}

The powder and crystalline compounds from different synthetic attempts were characterized using the powder XRD patterns taken in Bruker AXS Powder X-ray diffractometer for complexes 1-5. The experimentally obtained patterns were then compared with the simulated ones found from the single-crystal X-ray diffraction data. In all cases the as obtained experimental patterns show good agreement with the simulated ones (Figure S4 in SI). The slight differences in intensity in some $2 \theta$ values are due to the different orientations of the powder crystallites. From the similarity patterns thus obtained, we can conclude that the powder samples available from different batches of synthesis are phase pure and have the same composition to that of the single crystals grown from the solution medium.

\section{Electronic Spectra}

The solid state diffuse reflectance spectra (DRS) in 200-1200 nm range for 1-5 are characteristic and representative for their identity in the solid state (Figure S3 in SI). The characteristic peaks for ligand field transitions for distorted octahedral Niı centers in these aggregates are identified with certainty. The five low energy broad absorption bands at 987, 982, 987, 978 and 989 $\mathrm{nm}$ can be assigned for the spin allowed ${ }_{3} \mathrm{~A}_{2 \mathrm{~g}}(\mathrm{~F}) \rightarrow{ }_{3} \mathrm{~T}_{1 \mathrm{~g}}(\mathrm{~F})$ transitions for the five complexes 1-5 respectively. The next high energy absorption band for $3 \mathrm{~A}_{2 g}(\mathrm{~F}) \rightarrow 3 \mathrm{~T}_{1 \mathrm{~g}}(\mathrm{P})$ transitions are 
observed at $611,607,607,610$ and $610 \mathrm{~nm}$ respectively. The lowest energy ${ }_{3} \mathrm{~A}_{2 \mathrm{~g}}(\mathrm{~F}) \rightarrow{ }_{3} \mathrm{~T}_{2 \mathrm{~g}}(\mathrm{~F})$ transitions are not detected for any of these complexes. Whereas the peaks at 350, 350, 352, 345 and $346 \mathrm{~nm}$ are intense and assigne LMCT transitions. The intra-ligand $\pi \rightarrow$ as intense peaks at $288,268,294,261$ and $288 \mathrm{~nm}$ respectively for 1-5.

Description of Crystal Structures. X-ray quality block shaped gh evaporative crystallization from

Figure 1. POV-ray presentation of 3 with metal atom numbering scheme. $\mathrm{H}$ atoms and counter anions are omitted for clarity. Color code: $\mathrm{C}$, grey; $\mathrm{N}$, blue; $\mathrm{O}$, red; DyıI, cyan; Niı, green; $\mathrm{H}$, white.

(a)

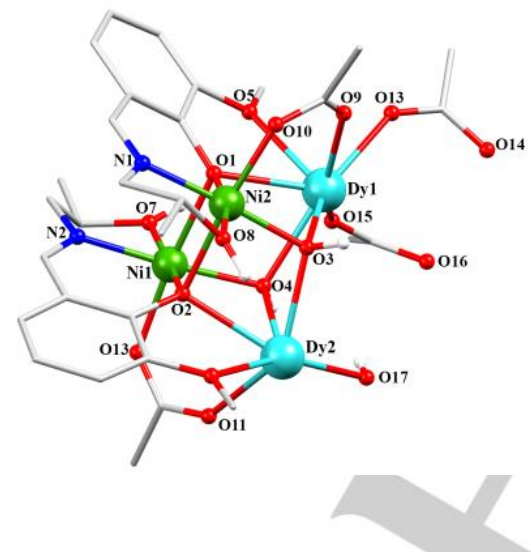

(b)

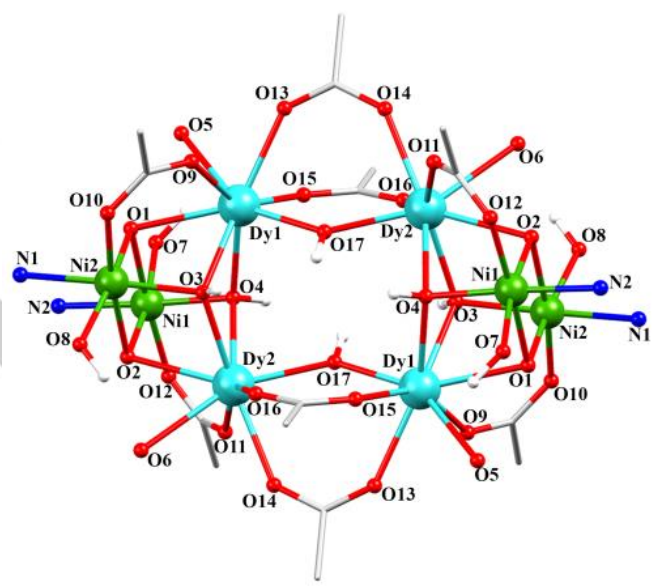

Figure 2. (a) POV-ray presentation of asymmetric unit of 3 and (b) the core structure with atom numbering scheme. $\mathrm{H}$ atoms and counter anions are omitted for clarity. Color code as above.

the reaction solutions after 5 days. The detail molecular structures of the complexes 1-5 were established from single crystal X-ray structure determinations. All the complexes are isostructural and only differ in the number of water molecules present within the crystal lattices. Complexes $\mathbf{1}, \mathbf{3}$ and $\mathbf{4}$ crystallize in the triclinic $P$ $\overline{\mathbf{1}}$ space group with $Z=1$, whereas 2 and $\mathbf{5}$ crystallize in the monoclinic $C 2 / \mathrm{m}$ space group with $Z=2$. The detail discussion is made for the structure of $\mathbf{3}$ as a representative case to illustrate the common structural features within the family.

$\left[\mathrm{Ni}_{4} \mathrm{Dy} 4(\mathrm{HL})_{4}\left(\mu_{2}-\mathrm{OH}\right)_{2}\left(\mu_{3}-\mathrm{OH}\right)_{4}\left(\mu-\mathrm{OOCCH}_{3}\right)_{8}\right]\left(\mathrm{NO}_{3}\right)_{2} \cdot 17 \mathrm{H}_{2} \mathrm{O}$ The molecular structure of 3 showing the triply bridging connectivity from the DyıI sides of two $\mathrm{Ni}_{2} \mathrm{Dy}_{2}$ cubic units is presented in Figure 1. The details of the crystal data and refinement parameters for $\mathbf{1 - 5}$ are summarized in Table 1. Selected interatomic separations and bond angles around the metal ion centers are listed in Table S4-S7. The asymmetric unit of 3 consists of a single $\mathrm{Ni}_{2} \mathrm{Dy}_{2}$ cubic core formed from two $\mathrm{HL}$ units, two DyıI ions, two Niı ions, four $\mathrm{AcO}$ - ions and three $\mathrm{HO}$ groups (Figure 2a). Two AcO- and one $\mathrm{HO}_{-}$ions are utilized to develop the separated double cubane $\mathrm{Ni}_{4} \mathrm{Dy}_{4}$ structure (Figure $2 b)$. The whole structure of 3 revealed a dicationic complex,
$\left[\mathrm{Ni}_{4} \mathrm{Dy}_{4}(\mathrm{HL})_{4}\left(\mu_{3}-\mathrm{OH}\right)_{4}\left(\mu_{2}-\mathrm{OH}\right)_{2}\left(\mu-\mathrm{OOCCH}_{3}\right)_{8}\right]_{2+}$, associated with two $\mathrm{NO}_{3}$ - ions available from the nitrate salt of $\mathrm{Dy}$ III and seventeen water of crystallization. Interestingly, the four AcO- ions originating from the Nill salt and two $\mathrm{HO}_{-}$ions from $\mathrm{LiOH}$ are consumed in stoichiometric amounts to establish the intertetramer bridges. Other AcO- and $\mathrm{HO}_{-}$bridges are utilized to sustain the individual cubic $\mathrm{Ni}_{2} \mathrm{Dy}_{2}$ units. The tridentate ONO pocket from one $\mathrm{HL}$ - showed meridional binding to one Niı center. Whereas the adjacent bidentate $\mathrm{OO}$ pocket is chosen to trap the hard, bigger and oxophilic Dy III center already attached to several $\mathrm{H}_{2} \mathrm{O}$ molecules in the reaction medium. De-protonation of one

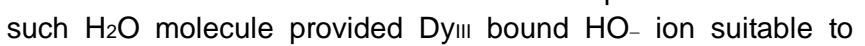
embrace the ligand anion bound entity as $\left\{\mathrm{NiDy}(\mathrm{HL})(\mathrm{OH})(\mathrm{OAc})\left(\mathrm{H}_{2} \mathrm{O}\right)\right.$ n\}. Two phenoxido donors from two $\mathrm{HL}$ - bridge two Niı centers to give the $\mathrm{Ni}_{2} \mathrm{O}_{2}$ face while two $\mathrm{HO}_{-}$ ions bridge two $\mathrm{Dy}$ III ions for $\mathrm{Dy}_{2} \mathrm{O}_{2}$ face.

Dy1 and Dy2 are double-bridged by two $\mu_{3}-\mathrm{O}$ atoms from two $\mathrm{HO}$ groups whose third arm is extended to $\mathrm{Ni} 1$ and $\mathrm{Ni} 2$ and thus form the $\mathrm{Dy}_{2} \mathrm{O}_{2}$ rhombus face. The $\mathrm{Ni}_{2} \mathrm{O}_{2}$ faces register $\mathrm{O}-\mathrm{Ni}-\mathrm{O}$ angles ranging from $81.65(12)^{\circ}$ to $81.72(12)^{\circ}$. Formation of two such $\mathrm{Dy}_{2} \mathrm{O}_{2}$ open faces is important to establish the inter-cubic 
connections for separated double-cubane arrangement. Two HLunits are involved in binding and assembling of one cubic $\mathrm{Ni}_{2} \mathrm{Ln}_{2}$ sub-unit. Each $\mathrm{MeO}-$ arm of the ligand anion ( $\mathrm{HL}_{-}$) is engaged in terminal coordination to Dy 1 il ions selectively and thus the central phenoxido group is allowed to bridge two other Niı ions. From the
$\mathrm{HL}$ - anions the available $\mathrm{PhO}$ - and the adjacent -OMe function made the bidentate 0,0 chelation available to DyIII centers providing narrow $\mathrm{O} 1-\mathrm{Dy} 1-\mathrm{O} 5$ angle of $60.67(11)^{\circ}$ and O2-Dy2O6 angle of $61.17(10)^{\circ}$. The $\mathrm{Ni} \cdots \mathrm{Ni}$ 
Table 1. Crystal data and refinement parameters for complexes 1-5.

\begin{tabular}{|c|c|c|c|c|c|}
\hline & $1(\mathrm{Ln}=\mathrm{Gd})$ & $2(\mathrm{Ln}=\mathrm{Tb})$ & 3(Ln=Dy) & $4(\mathrm{Ln}=\mathrm{Ho})$ & $5(\mathrm{Ln}=\mathrm{Yb})$ \\
\hline Empirical formula & $\mathrm{C}_{60} \mathrm{H}_{90} \mathrm{Gd}_{4} \mathrm{~N}_{6} \mathrm{Ni}_{4} \mathrm{O}_{42}$ & $\mathrm{C}_{60} \mathrm{H}_{90} \mathrm{~Tb}_{4} \mathrm{~N}_{6} \mathrm{Ni}_{4} \mathrm{O}_{42}$ & $\mathrm{C}_{60} \mathrm{H}_{90} \mathrm{Dy}_{4} \mathrm{~N}_{6} \mathrm{Ni}_{4} \mathrm{O}_{42}$ & $\mathrm{C}_{60} \mathrm{H}_{90} \mathrm{H}_{4} \mathrm{~N}_{6} \mathrm{Ni}_{4} \mathrm{O}_{4}$ & $\mathrm{C}_{60} \mathrm{H}_{90} \mathrm{Yb}_{4} \mathrm{~N}_{6} \mathrm{Ni}_{4} \mathrm{O}_{42}$ \\
\hline Formula weight & 2431.21 & 2437.89 & 2452.21 & 2461.93 & 2494.34 \\
\hline Crystal system & Triclinic & Monoclinic & Triclinic & Triclinic & Monoclinic \\
\hline Space group & $P \overline{\mathbf{I}}$ & $C 2 / m$ & $P \overline{\mathbb{1}}$ & $P \overline{\mathbb{1}}$ & $C 2 / \mathrm{m}$ \\
\hline a $(\AA ̊)$ & $12.9729(8)$ & $16.631(7)$ & $13.152(11)$ & $12.9782(10)$ & $16.67(3)$ \\
\hline$b(\AA)$ & $14.6039(9)$ & $28.317(6)$ & $14.926(9)$ & $14.6759(11)$ & $28.06(6)$ \\
\hline$c(\AA)$ & $15.2051(10)$ & $17.244(5)$ & $15.426(8)$ & $15.2575(11)$ & $17.27(3)$ \\
\hline$\alpha(0)$ & $113.636(2)$ & 90 & $113.794(10)$ & $114.549(2)$ & 90 \\
\hline$\beta(0)$ & $111.059(2)$ & $141.891(15)$ & $110.409(16)$ & $111.040(2)$ & $142.67(2)$ \\
\hline Y (o) & $93.730(2)$ & 90 & $94.62(3)$ & $93.334(2)$ & 90 \\
\hline Volume $\left(\AA_{3}\right)$ & $2388.0(3)$ & $5012(3)$ & $2509(3)$ & $2392.4(3)$ & $4901(16)$ \\
\hline Z & 1 & 2 & 1 & 1 & 2 \\
\hline$D_{\text {calcd }}(\mathrm{g} \mathrm{cm}-3)$ & 1.691 & 1.615 & 1.623 & 1.709 & 1.688 \\
\hline $\begin{array}{c}\text { Absorption } \\
\text { coefficient }(\mathrm{mm}-1)\end{array}$ & 3.589 & 3.596 & 3.751 & 4.118 & 4.608 \\
\hline$F(000)$ & 1196 & 2400 & 1204 & 1208 & 2432 \\
\hline Temperature/K & 196.15 & 180.0 & 196.96 & $196(2)$ & 150.0 \\
\hline $\begin{array}{c}\text { Reflections } \\
\text { collected/unique }\end{array}$ & $34041 / 12924$ & 24267 / 5694 & $23805 / 11347$ & $28710 / 8530$ & $23061 / 5617$ \\
\hline Parameters & 573 & 292 & 537 & 534 & 287 \\
\hline limiting indices & $\begin{array}{c}-16 \leq \mathrm{h} \leq 18,-20 \leq \mathrm{k} \\
\leq 20,-20 \leq \mathrm{I} \leq 22\end{array}$ & $\begin{array}{c}-21 \leq \mathrm{h} \leq 20,-36 \leq \mathrm{k} \\
\leq 31,-19 \leq \mathrm{I} \leq 22\end{array}$ & $\begin{array}{c}-16 \leq \mathrm{h} \leq 17,-19 \leq \mathrm{k} \\
\leq 12,-20 \leq \mathrm{I} \leq 20\end{array}$ & $\begin{array}{c}-15 \leq \mathrm{h} \leq 15,-17 \leq \mathrm{k} \\
\leq 17,-18 \leq \mathrm{I} \leq 18\end{array}$ & $\begin{array}{c}-21 \leq \mathrm{h} \leq 21,-35 \leq \mathrm{k} \\
\leq 36,-22 \leq \mathrm{I} \leq 22\end{array}$ \\
\hline $\begin{array}{l}\text { Goodness-of-fit } \\
\qquad\left(F_{2}\right)\end{array}$ & 1.036 & 1.088 & 1.062 & 1.031 & 1.041 \\
\hline $\begin{array}{c}\text { Largest diff } \\
\text { peak/ hole (e } \\
\AA-3)\end{array}$ & $3.914,-2.443$ & $1.803,-1.082$ & $1.706,-3.226$ & $1.918,-1.191$ & $2.831,-1.608$ \\
\hline Rint & 0.0288 & 0.0377 & 0.0451 & 0.0515 & 0.0765 \\
\hline $\begin{array}{l}R 1 ; w R 2[I \\
\quad>2 \sigma(I)]\end{array}$ & $0.0477 ; 0.1385$ & $0.0329 ; 0.0707$ & $0.0435 ; 0.1180$ & $0.0361 ; 0.0867$ & $0.0403 ; 0.0926$ \\
\hline CCDC & 1989262 & 1989264 & 1989261 & 1989265 & 1989263 \\
\hline
\end{tabular}


(a)

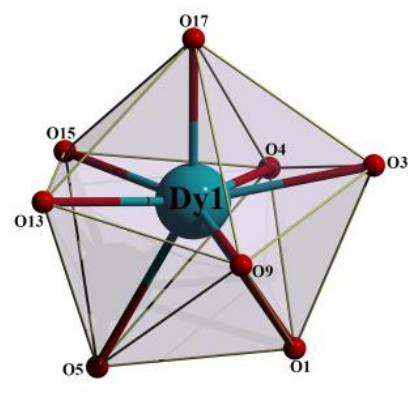

(b)

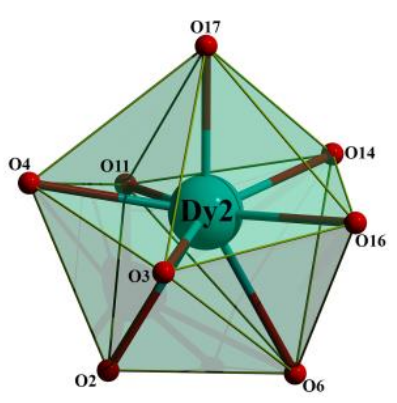

(c)

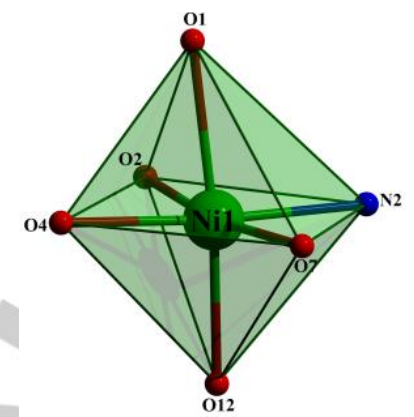

Figure 3. (a) and (b) Distorted trigonal dodecahedral coordination environment around the Dy1 III and Dy2III center; (c) Distorted octahedral coordination environment around the Niı center. Color code: O, red; N, blue; DyıI, cyan; Niı, green.

separation within each $\mathrm{Ni}_{2} \mathrm{Dy} 2$ cube structure is shortest at 3.245 $\AA$. The Dy1 $\cdots$ Dy2 separation is longest $\left(3.929 \AA\right.$ ) at the $\mathrm{Dy}_{2} \mathrm{O}_{2}$ rhombus face. Coordination of two imine $\mathrm{N}$ donors from $\mathrm{HL}$ - are utilized to bind two Niı centers giving normal $\mathrm{Ni}-\mathrm{N}$ distances of 2.009(4) and 2.015(4) $\AA$. The O donors from the alcohol OH arms showed chelation with slightly longer $\mathrm{Ni}-\mathrm{O}(\mathrm{H})$ bonds of $2.088(4)$ $\AA$ and 2.095(4) Å. Two AcO- ions in $\mu 1,3$ mode span two $\mathrm{Ni}$...Dy faces providing Ni1..Dy2 and Ni2..Dy1 separations of $3.420 \AA$ and $3.432 \AA$ respectively, which are of intermediate type. Two other $\mathrm{Ni}$...Dy faces, devoid of acetato-bridges register higher magnitude of $\mathrm{Ni}$...Dy separations at $3.579 \AA$ and $3.557 \AA$ for $\mathrm{Ni} 1$...Dy1 and Ni2...Dy2 respectively. The bigger Dy 1 .I centers at the two corners of each cube thus have vacant coordination sites to attract other donors. One DyIII from each cube thus binds two AcO- and one HO- units and link another DyIII center of $\mathrm{Dy}_{2} \mathrm{O}_{2}$ face of adjacent cube. Two such $(\mathrm{AcO})_{2}(\mathrm{HO})$ bridges are thus utilized to connect two $\mathrm{Ni}_{2} \mathrm{Dy}_{2}$ cubes registering long inter-

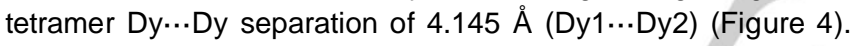
The crystal packing diagram reveals the shortest Dy...Dy distance between neighboring molecule is $9.730 \AA$ (Figure S6). Within the octameric structure all four Niıl centers remain in distorted octahedral $\mathrm{O}_{5} \mathrm{~N}$ coordination geometry (Figure $3 \mathrm{~b}$ ) as verified from Continuous Shape Measures (CShM) by using SHAPE 2.121 (Table S3). Amongst the five oxygen donors, two are from phenoxido group, one each from ligand alcohol arm and bridging hydroxido group, and the fifth one from acetato group. The Ni-O distances vary within 2.004(3)-2.262(3) $\AA$, in which the shortest one is found for hydroxido oxygen (Ni2-O3) and longest one for phenoxido oxygen (Ni2-O2). The extent of distortion from the ideal octahedral geometry is detected from the narrower $\mathrm{O}$ $\mathrm{Ni}-\mathrm{O}$ adjacent angles of $80.37(12)$ and $81.34(12)^{\circ}$, and opposite $\mathrm{O}-\mathrm{Ni}-\mathrm{O}$ angles of $173.38(12)$ and $174.68(13)^{\circ}$. The $\mathrm{O}_{8}$ coordination geometry around each DyIII center is distorted trigonal dodecahedral (Figure 3a) one as verified from CShM (Table S2). The trigonal dodecahedral coordination geometry around the four bigger DyıII ions forces a distortion around the coordination environment of adjacent $\mathrm{Ni}$ il ions. The eight $\mathrm{O}$ donors are assembled from one ligand PhO- (Dy1-01, 2.474(3) Aं; Dy2O2, 2.456(3) $\AA$ ), one ligand -OMe group (Dy1-O5, 2.597(3); Dy2-O6, 2.593(4) A), two $\mu_{3}-\mathrm{HO}_{-}(\mathrm{Dy}-\mathrm{O}, 2.369(3)-2.437(3) \AA$ ), one $\mu 2$-HO- (Dy1-O17, 2.260(3); Dy2-O17, 2.258(4) $\AA$ ) and three bridging acetato (Dy-O, 2.338(4)-2.373(4) $\AA$ ) groups. The ligand derived -OMe functions around each DyıI ions thus record the longest $\mathrm{Dy}-\mathrm{O}$ bonds. The oxygen atoms from $\mu_{3}-\mathrm{HO}$ - donors $(\mathrm{O} 3$,
O4) provide O-Dy-O angles of $67.09(11)^{\circ}$ and $66.61(11)^{\circ}$. Other $\mathrm{O}-\mathrm{Dy}-\mathrm{O}$ angles vary within $61.17(10)^{\circ}$ to $151.50(11)^{\circ}$. The $\mu_{3}$ bridging nature of $\mathrm{HO}$ - groups $(\mathrm{O} 3$ and $\mathrm{O} 4)$ at the corners of the cube record Dy1-O3-Dy2 and Dy1-O4-Dy2 angles of $109.48(12)^{\circ}$ and $109.66(12)^{\circ}$ respectively, which are away from angles close to $90^{\circ}$ commonly observed for isolated $\mathrm{Ni}_{4} \mathrm{O}_{4}$ type cube structures.22 The Dy1-O3-Ni2, Dy2-O3-Ni2, Dy1-O4-Ni1 and Dy2-O4-Ni1 angle on the other hand span from 99.69(13) ${ }^{\circ}$ to $108.88(14)^{\circ}$. Lengthening of bonds at the shared $\mu_{3}$ type HOand PhO- bridge heads, due to presence of DyıI ions ultimately lead to distortion around the adjacent Niı ions.

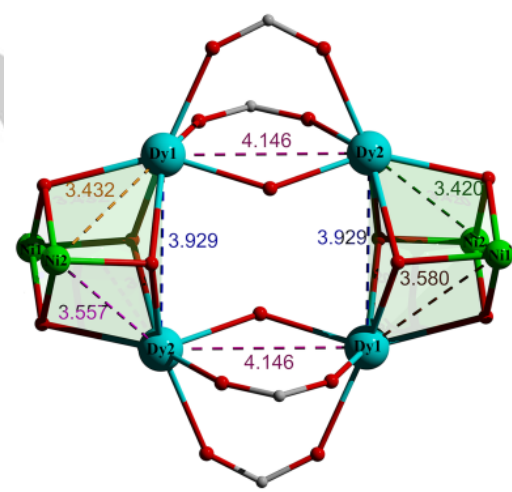

Figure 4. Metallic core view of complex 3 showing intermetallic separations

\section{Discussion of magnetic properties}

Magnetic susceptibility data for the complexes $1-5$ were collected at $200 \mathrm{Oe}(2-30 \mathrm{~K})$ and $3000 \mathrm{Oe}(2-300 \mathrm{~K})$. The temperature dependence plot of $\chi \mathrm{T}$ at $2-300 \mathrm{~K}$ are shown in Figure 5 . The relevant susceptibility and saturation magnetization data for all complexes are collected in Table 2.

The $\chi T$ values at $300 \mathrm{~K}$ are in agreement with the expected theoretical values for four Niı $(S=1, g=2.0)$ and four Lnı ions, taking into account the spin-only moment for complex $\mathbf{1}$ or strong spin-orbit coupling for complexes $\mathbf{2}-\mathbf{5}$. The $\chi \top$ products are mostly constant down to $100 \mathrm{~K}$, between $100 \mathrm{~K}$ and $30 \mathrm{~K}$ there is a slight decrease in $\chi^{\top}$ for all except 1 and below $30 \mathrm{~K}$ an increase is observed in all cases. The low temperature increase indicates ferromagnetic interactions between the metal ions that from complexes $\mathbf{1}$ to $\mathbf{5}$, this increase is field dependent. A slight decrease in $\chi^{\top}$ observed for $2-5$ between $100 \mathrm{~K}$ and 30 
Table 2. Comparison of calculated and experimental $\chi^{\top}$ data

\begin{tabular}{|c|c|c|c|c|}
\hline Complexes & $\chi^{\top}\left(300 \mathrm{~K}, \mathrm{~cm}_{3} \mathrm{~K} \mathrm{~mol}-1\right)$ & $\begin{array}{c}\text { Expected } \chi^{\mathrm{T}}\left(300 \mathrm{~K}, \mathrm{~cm}_{3}\right. \\
\mathrm{K} \text { mol-1) }\end{array}$ & $\mathrm{Ni}(I I), \mathrm{S}=1, \mathrm{~g}=2.0$ & $\begin{array}{c}\mathrm{M} / \mathrm{NA \mu \textrm {B }}(2 \\
\mathrm{K})\end{array}$ \\
\hline 1 & 34.13 & 35.6 & ${ }_{8} S_{7 / 2}, S=7 / 2, L=0, g=2.0$ & 33.00 \\
\hline 2 & 46.48 & 51.24 & ${ }_{7} F_{6}, S=3, L=3, J=6$ and $g J=3 / 2$ & 22.82 \\
\hline 3 & 55.65 & 60.64 & ${ }_{6} \mathrm{H}_{15 / 2}, \mathrm{~S}=5 / 2, \mathrm{~L}=5, \mathrm{~J}=15 / 2$ and $\mathrm{g} J=4 / 3$ & 26.41 \\
\hline 4 & 54.36 & 60 & $5 l_{8}, S=2, L=6, J=8$ and $g J=10 / 8$ & 27.13 \\
\hline 5 & 13.53 & 14 & ${ }_{2} F_{7 / 2}, S=1 / 2, L=3, J=7 / 2$ and $g J=1.19$ & 13.03 \\
\hline
\end{tabular}

$\mathrm{K}$ can be attributed to the depopulation of $M\lrcorner$ sublevels of the lanthanoid ion.

The crystal structures of the complexes show the linking of two $\mathrm{Ni}_{2} \mathrm{Ln}_{2}$ cubanes by four $\mathrm{AcO}$ - and $\mathrm{HO}_{-}$ancillary bridges as shown in Scheme 2. In each cubane part the $\mathrm{Ni}-\mathrm{O}-\mathrm{Ni}$ angles are $98.06(15)^{\circ}$ and $98.84(16)^{\circ}, 98.0(2)^{\circ}$ and $98.00(2)^{\circ}, 98.80(12)^{\circ}$ and $97.82(12)^{\circ}, 98.67(16)^{\circ}$ and $97.89(15)^{\circ}$, and $95.70(3)^{\circ}$ and $96.00(3)^{\circ}$ for complexes 1-5 respectively. The $\mathrm{Ni}-\mathrm{O}-\mathrm{Ln}$ angles on the other hand are between $97.68^{\circ}$ and $108.85^{\circ}$ and $\mathrm{Ln}-\mathrm{O}-\mathrm{Ln}$ angles remain between $108.97^{\circ}$ to $111.75^{\circ}$ for the all the five complexes. The $\mathrm{Ni} \cdots \mathrm{Ni}$ exchange coupling is expected to be ferromagnetic in nature for $\mathrm{Ni}-\mathrm{O}-\mathrm{Ni}$ angles of $98^{\circ}$ or less but when the $\mathrm{Ni}-\mathrm{O}-\mathrm{Ni}$ angle is $98^{\circ}$ or more, the coupling can be antiferromagnetic in nature.23 The coupling between Niı and LnıI can be either ferromagnetic or antiferromagnetic, but as usual the $3 \mathrm{~d}-4 \mathrm{f}$ coupling is very weak.7a,24 Each $\mathrm{Ni}_{2} \mathrm{Ln}_{2}$ unit is linked to another one forming a octamer through the $\mathrm{Ln}_{2} \mathrm{O}_{2}$ face of each cubane part. The $\mathrm{Ln}-\mathrm{Ln}$ distance is quite long, $4.107 \AA-4.145 \AA$ for complexes 1-5, thus the coupling between $\mathrm{Ni}_{2} \mathrm{Ln}_{2}$ units will be in turn very weak.

Magnetization vs. field plots at $2 \mathrm{~K}$ are shown in Figure 6 . They clearly show for all species the population of a magnetic ground state, consistent with the existence of some component of ferromagnetic coupling in the complexes. The susceptibility and magnetization data for $\mathbf{1}$ was fitted using the software $\mathrm{PHI} .25$ The model was a simple $\mathrm{Ni}_{2} \mathrm{Ln}_{2}$ unit with intermolecular interactions included as $z J$ ' exchange. The program was designed for the treatment of systems containing orbitally degenerate and strongly anisotropic ions, through the inclusion of a full Hamiltonian with Exchange, Zeeman, Spin-orbit coupling and Crystal Field effects, as shown in Equation 2. In our simple model, crystal field effects on the Niı were not included to avoid overparameterization and $g$ was fixed as 2.0 for all ions. Equation 3 shows the full exchange Hamiltonian used in PHI.

$$
\begin{gathered}
\widehat{H}=\widehat{H}_{S O}+\widehat{H}_{E X}+\widehat{H}_{C F}+\widehat{H}_{Z E E} \\
\widehat{H}_{E X}=-2 \sum_{i<j}^{i, j \in N} \overrightarrow{\hat{S}}_{i} \cdot \overline{\overline{J_{l \jmath}}} \cdot \overrightarrow{\hat{S}}_{j}=\widehat{H}_{(\text {an }) i s o}+\widehat{H}_{\text {anti }}
\end{gathered}
$$

The best fit was obtained for $J_{1}(\mathrm{Ni}-\mathrm{Ni})=-0.767 \mathrm{~cm}-1, J_{2}(\mathrm{Gd}-\mathrm{Gd})$ $=0.144 \mathrm{~cm}-1$ and $J_{3}(\mathrm{Ni}-\mathrm{Gd})=-0.037 \mathrm{~cm}-1$. As expected, the inter$\mathrm{Ni}_{2} \mathrm{Gd}_{2}$ unit is the smallest, with a value of $J\left(\mathrm{Ni}_{2} \mathrm{Gd}_{2}-\mathrm{Ni}_{2} \mathrm{Gd}_{2}\right)=\mathrm{ZJ}^{\prime}$ $=0.0013 \mathrm{~cm}-1$. The exchange couplings are all small, as expected and $J(\mathrm{Ni}-\mathrm{Ni})$ is antiferromagnetic, in agreement with the exchange values tabulated for various other Niı cubanes with $\mathrm{Ni}-\mathrm{O}-\mathrm{Ni}$ angles of $98^{\circ}$ or larger. The Gd-Gd exchange coupling is according to the fitting small but ferromagnetic while the $\mathrm{Ni}-\mathrm{Gd}$ coupling is small and antiferromagnetic. In the structure $\mathrm{Ni}-\mathrm{O}-\mathrm{Ln}$ angles are $97.67^{\circ}$ to $99.23^{\circ}$ and $\mathrm{Ni}-\mathrm{OH}-\mathrm{Ln}$ are between $99.68^{\circ}$ and $108.29^{\circ}$, while there is also a syn,syn- carboxylato bridge. With these structural parameters, weak ferromagnetic coupling should be expected for adjacent Ln-Ni centers mediated by the monoatomic oxygen bridges while an antiferromagnetic contribution is expected for the syn,syn-carboxylato pathway. This result in a very small, near zero exchange coupling between $\mathrm{Ni}-\mathrm{Gd}$, as calculated by the best fit. We can compare this complex with our previously
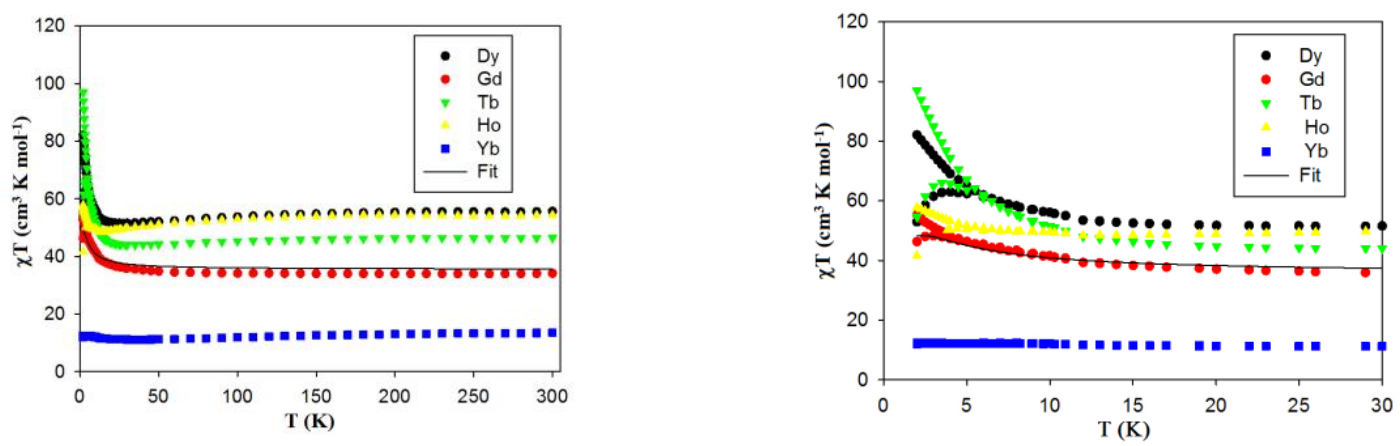

Figure 5. Temperature dependence susceptibility $(\chi T)$ data for complexes 1-5 measured with a dc field of 3000 Oe (left), and the low temperature region with a dc field of 198 Oe for clarity (right). The solid black line is a fit of the experimental data for complex 1 . 


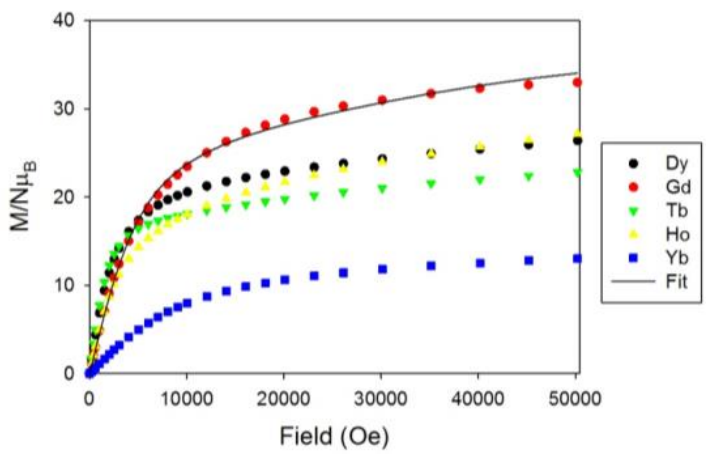

Figure 6. Field dependence of magnetization for complexes $\mathbf{1 - 5}$ at $2 \mathrm{~K}$.

reported $\mathrm{Ni}_{2} \mathrm{Gd}_{2}$ cubane.26 In those cubanes we observed very weak ferromagnetic $\mathrm{Gd}-\mathrm{Gd}$ and $\mathrm{Ni}-\mathrm{Gd}$ interactions. The exchange constants are very similar, obtained with the same fitting software, to the ones reported here, but the small distortions imposed by the aggregation of the cubanes into a Ni4 Ln 4 unit can be responsible for the small differences observed, in particular the $\mathrm{Ni}-\mathrm{Gd}$ exchange constant. The main distortion is the Ln-Ln separation in $\mathrm{Ni}_{4} \mathrm{Ln}_{4}$ (3.91 $\AA$ for $\mathrm{Ni}_{4} \mathrm{Gd}_{4}$ complex vs $3.78 \AA$ for $\mathrm{Ni}_{2} \mathrm{Gd}_{2}$ ). The exchange values result in an $S=14$ spin ground state for $\mathbf{1}(\mathrm{Gd})$, due to the weak ferromagnetic coupling between two $\mathrm{Ni}_{2} \mathrm{Gd}_{2}$ units. However, due to the combination of weak exchange both ferromagnetic and antiferromagnetic there is some degree of frustration in the system and the ground state is not isolated from several excited states that span a few $\mathrm{cm}-1$ in energy.
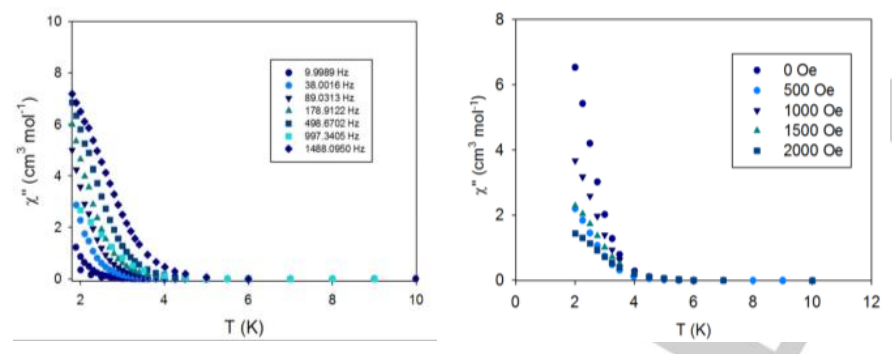

Figure 7. Out-of-phase ac magnetic susceptibility for $\mathbf{3}$ without applied dc field at the indicated frequencies (left) and at the indicated dc fields (right).

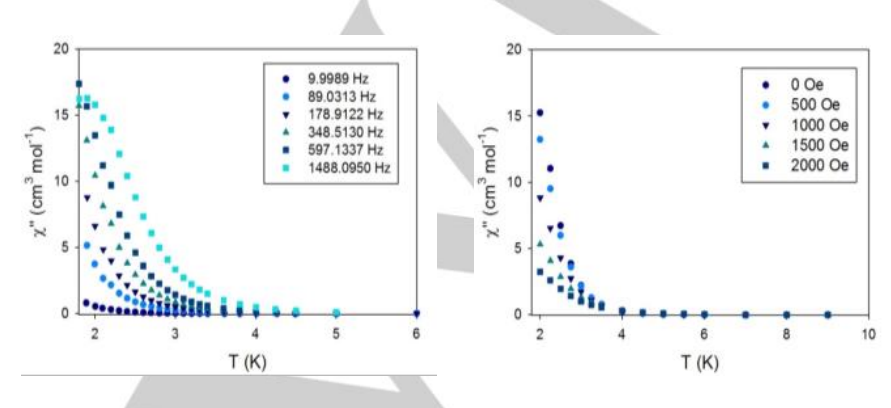

Figure 8. Out-of-phase ac magnetic susceptibility for $\mathbf{2}$ without applied dc field at the indicated frequencies (left) and at the indicated dc fields (right).

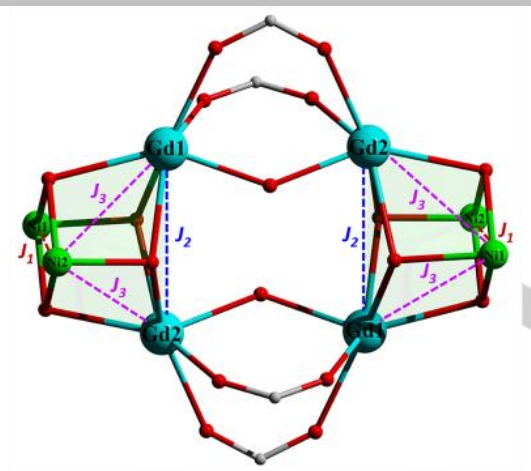

Scheme 2. Magnetic coupling interactions in complex 1. Niı green, Ln॥I cyan.

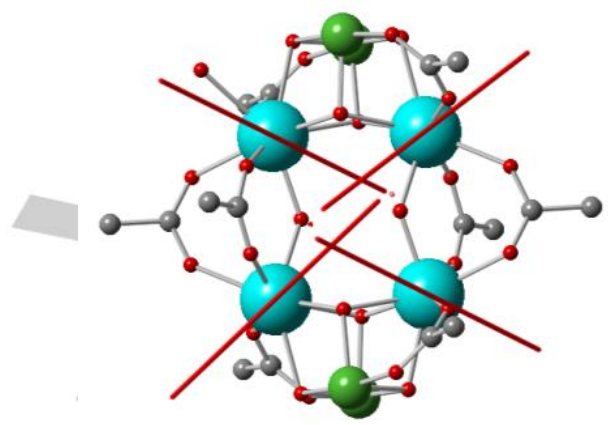

Figure 9. Views of the orientation of the anisotropy axes on the DyıI ions of $\mathrm{Ni}_{4} \mathrm{Dy} 4$, calculated by Magellan and depicted as red solid lines.

The dynamics of magnetization relaxation for these complexes was studied by ac magnetic susceptibility and are shown in Figure 7 and Figure 8. Only 2 and 3 showed tails of peak in the out-ofphase ac magnetic susceptibility when no dc field was applied during the measurement. Both $\mathbf{2}$ and $\mathbf{3}$ are SMMs with low blocking temperatures typical of $3 d-4 f$ SMMs. For $\mathbf{3}$, the peak is not fully observed if a dc field is applied. The results are similar for 2. This indicates fast relaxation for these complexes, probably due to QTM. Neither of the other complexes is an SMM.

The fitting of the susceptibility and magnetization data for $\mathbf{1}$ indicated that the anisotropy of the four Niı ions was not a key parameter in the magnetic properties. This has been observed before while comparing analogous Niı and Coı complexes.27 Thus, only for the most anisotropic lanthanide ions Dy III and TbıI the SMM behavior are observed. Since only the tail of an out-of-phase peak is observed down to $2 \mathrm{~K}$, this indicates that relaxation of the magnetization is still fast at these low temperatures for both $\mathbf{2}$ and 3.

The software Magellan28 has been used to calculate the orientation of the anisotropy axes on the DyıI ions of the Dy analogue 3. The software uses a purely electrostatic model for the calculation. As can be observed in Figure 9, the anisotropy axes on the two Dy of each $\mathrm{Ni}_{2} \mathrm{Dy}_{2}$ cubane are not oriented parallel to each other, in fact they are at a $43^{\circ}$ angle. This results in small molecular anisotropy, and thus it agrees well with observed dynamic properties of $\mathbf{3}$ : that is the absence of a large energy barrier for the relaxation of the magnetization. Furthermore, one can compare the coordination polyhedra around the TbIII and Dy III ions, shown in Figure 3. Clearly, the distorted geometry observed does not agree with a sandwich-like distribution of the ligands.29 
Using the same simple prediction $\mathrm{Yb}$ should display SMM properties with this equatorial ligand arrangement, but the low spin ground state and the lack of ferromagnetic interactions precludes the observation of SMM properties in the $\mathrm{Yb}$ analogue 5. There are few polynuclear SMMs reported with $\mathrm{Yb}$, since the $\mathrm{Yb} \cdots \mathrm{Yb}$ coupling is extremely weak.30

\section{Conclusion}

Coordinating self-aggregation reactions of $\mathrm{H}_{2} \mathrm{~L}$ and base with $\mathrm{Ni}(\mathrm{OAc})_{2} \cdot 4 \mathrm{H}_{2} \mathrm{O}$ and nitrate salts of five lanthanide(III) ions show results for a unique type of self-assembly for selected $3 d$ and $4 f$ block metal ions. Isolation of five $\mathrm{Ni}_{4} \mathrm{Ln}_{4}$ aggregates is achieved by bridging two $\mathrm{Ni}_{2} \mathrm{Ln}_{2}$ units, grown on ligand support, by four $\mathrm{AcO}-$ and two $\mathrm{HO}-$ groups giving two new $\mathrm{Ln}_{2} \mathrm{O}_{2}$ faces. The aggregation process is driven by the higher coordination demand of $4 \mathrm{f}$ ions attached to the $\mathrm{HL}$ - through bidentate $\mathrm{O}, \mathrm{OMe}$ part. These coordination positions are not fulfilled by terminal coordination of solvent and/or water molecules to inhibit the formation of octanuclear entities. The choice of $\mathrm{LiOH}$ as base is optimum for the generation of $\mathrm{HL}$-. In situ generation, entrapment and bridging by six $\mathrm{HO}_{-}$groups controls the formation of octanuclear complexes in chosen reaction condition. Thus in situ generation and ready availability of $\mathrm{HL}$ - bound $\mathrm{Ln}(\mathrm{OH})_{n}$ species is central for incorporation of four each $3 \mathrm{~d}$ and $4 \mathrm{f}$ ions in the resulting products. Use of $\mathrm{Ni}(\mathrm{OAc})_{2}$ provides $\mathrm{AcO}$ - ions for face clipping of individual $\mathrm{Ni}_{2} \mathrm{Ln} 2$ cubes as well as in inter-cube connections from the LnII vertices and establishment of the $3 d \cdots 4 f$ and $4 f \cdots 4 f$ links. These two types of networking anions have been exploited to control the particular type of molecular topology within the final products. The variable temperature magnetization measurements indicate a small ferromagnetic interaction for all the complexes. Complexes $\mathbf{2}$ and $\mathbf{3}$ show a tail in frequency-dependent out-ofphase ac signal without applied dc field. In this example we succeed in getting a small ferromagnetic $\mathrm{Ni}_{2} \mathrm{Ln}_{2} \cdots \mathrm{Ln}_{2} \mathrm{Ni}_{2}$ interaction and two new $\mathrm{Ni}_{4} \mathrm{~Tb}_{4}$ (2) and $\mathrm{Ni}_{4} \mathrm{Dy}_{4}$ (3) $\mathrm{SMMs}_{\text {sith }}$ appropriate ferromagnetic coupling. In general, the reported work supplemented the octanuclear family of Niı-LnII SMMs and added sensible approaches to the syntheses and isolation of $3 d-4 f$ SMMs having new structures and important magnetic properties.

\section{Experimental Section}

Materials and Reagents. All the chemicals and reagents used in this work were obtained from the commercial houses and used directly without any further purification. The typical sources were nickel acetate from Loba Chemie, India, and different lanthanide nitrates, 1-amino-2-propanol from Alfa Aesar, India. o-vanillin was obtained from Spectrochem Pvt. Ltd., India and used as received. $\mathrm{MeOH}$ and $\mathrm{MeCN}$ were reagent grade and obtained from Finar Ltd., India.

Ligand Synthesis. The Schiff base 2-[\{(2-hydroxypropyl)imino\}methyl]-6methoxyphenol $\left(\mathrm{H}_{2} \mathrm{~L}\right)$ was prepared in situ from a one-step condensation reaction of o-vanillin and 1-amino-2-propanol in a 1:1 molar ratio in $\mathrm{MeOH}$ under refluxing condition, as reported earlier.31 The obtained solution of $\mathrm{H}_{2} \mathrm{~L}$ was then directly used without isolation and further purification for the different synthesis using different combinations of $3 d$ and $4 f$ ions.

General Synthetic Procedure for Complexes 1-5. All the five complexes were prepared from the typical reactions of $\mathrm{H}_{2} \mathrm{~L}$ with the
nickel(II) and lanthanide(III) salts in the presence of stoichiometric amount of $\mathrm{LiOH}$ base in a mixed solvent media (Scheme 3). To a $\mathrm{MeCN}-\mathrm{MeOH}$ (3:1) solution of $\mathrm{H}_{2} \mathrm{~L}(0.1 \mathrm{mmol})$ solid $\mathrm{Ln}\left(\mathrm{NO}_{3}\right) \cdot \mathrm{nH}_{2} \mathrm{O}(0.1 \mathrm{mmol})$ was added under stirring condition to obtain a light yellow solution. After $10 \mathrm{~min}$ of stirring, solid $\mathrm{LiOH}(0.2 \mathrm{mmol})$ was added and the solution was stirred for 1 h. To this another $\mathrm{MeOH}$ solution of $\mathrm{Ni}\left(\mathrm{CH}_{3} \mathrm{COO}\right)_{2} \cdot 4 \mathrm{H}_{2} \mathrm{O}(0.1 \mathrm{mmol})$ was added and the whole mixture was further stirred for $7 \mathrm{~h}$ period to obtain a green solution, which was next filtered and kept for slow evaporation of solvents in air. Green colored block shaped crystals, suitable for X-ray analysis, were separated out from the solution after 5 days. The stoichiometry of the used reagents and the characterization data of each complex (1-5) are delineated below.

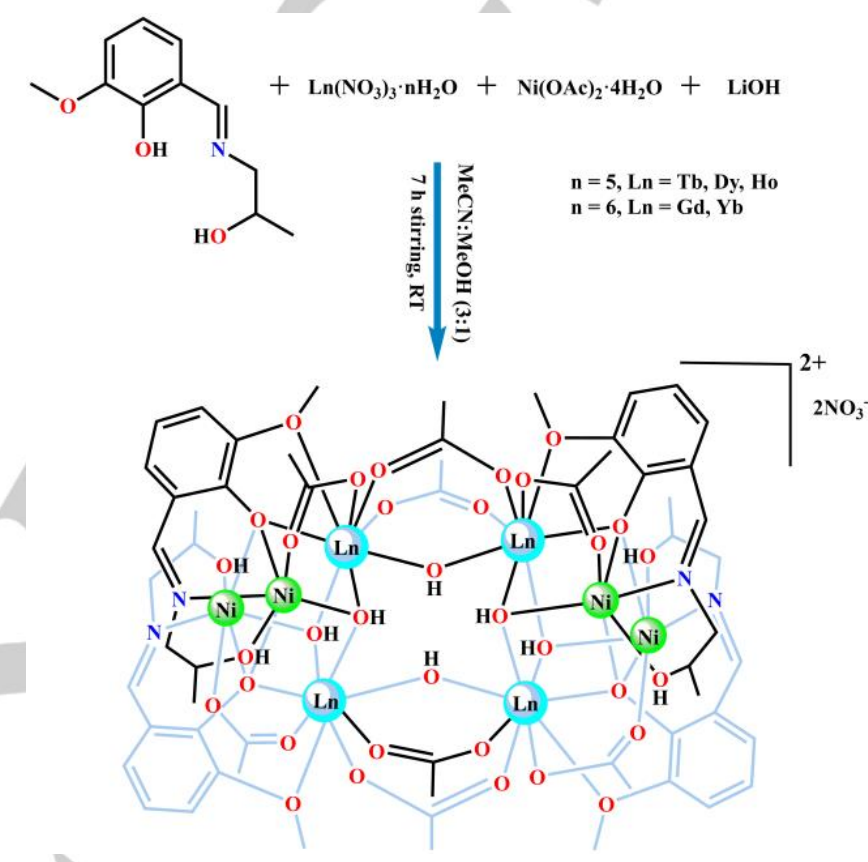

Scheme 3. Syntheses of complexes 1-5

$\left[\mathrm{Ni}_{4} \mathrm{Gd}_{4}(\mathrm{HL})_{4}\left(\mu_{2}-\mathrm{OH}\right)_{2}\left(\mu_{3}-\mathrm{OH}\right)_{4}\left(\mu-\mathrm{OOCCH}_{3}\right)_{8}\right] \cdot\left(\mathrm{NO}_{3}\right)_{2} \cdot 1_{2} \mathrm{H}_{2} \mathrm{O} \quad$ (1). $\mathrm{H}_{2} \mathrm{~L}$ $(1 \mathrm{~mL}, \quad 0.1 \mathrm{mmol}), \quad \mathrm{Gd}\left(\mathrm{NO}_{3}\right)_{3} \cdot 6 \mathrm{H}_{2} \mathrm{O} \quad(0.0451 \mathrm{~g} \quad, \quad 0.1 \mathrm{mmol})$, $\mathrm{Ni}\left(\mathrm{CH}_{3} \mathrm{COO}\right)_{2} \cdot 4 \mathrm{H}_{2} \mathrm{O}(0.0260 \mathrm{~g}, 0.1 \mathrm{mmol})$ and $\mathrm{LiOH}(0.0840 \mathrm{~g}, 0.2 \mathrm{mmol})$. Yield: $0.045 \mathrm{~g} ; 75 \%$ based on $\mathrm{Gd}$. Anal. Calcd for $\mathrm{C}_{60} \mathrm{H}_{110} \mathrm{Gd}_{4} \mathrm{Ni}_{4} \mathrm{~N}_{6} \mathrm{O}_{52}$ (2611.30) C, 27.60; H, 4.25; N, 3.22. Found: C, 27.48 H, 4.14; N; 3.13. Selected FT-IR peaks $(\mathrm{KBr}, \mathrm{cm}-1 ; \mathrm{s}=$ strong, vs $=$ very strong, $\mathrm{m}=$ medium, br = broad): $3377(\mathrm{br}), 1651(\mathrm{~m}), 1605(\mathrm{~m}), 1565(\mathrm{~s}), 1464(\mathrm{~m}), 1411(\mathrm{vs})$, 1338 (vs), $1264(\mathrm{~s}), 1243(\mathrm{~m}), 1223(\mathrm{~m}), 1078(\mathrm{~m}), 1033(\mathrm{~m}), 967(\mathrm{w})$, 849(w), $750(\mathrm{~m}), 643(\mathrm{~m})$. UV-vis spectra in MeOH: $\lambda \max , \mathrm{nm}(\varepsilon, \mathrm{L} \mathrm{mol}-1$ cm-1) 609 (3291), 374 (16369), 278 (33498), 234 (98551), 208 (78138).

$\left[\mathrm{Ni}_{4} \mathrm{~Tb}_{4}(\mathrm{HL})_{4}\left(\mu_{2}-\mathrm{OH}\right)_{2}\left(\mu_{3}-\mathrm{OH}\right)_{4}\left(\mu-\mathrm{OOCCH}_{3}\right)_{8}\right] \cdot\left(\mathrm{NO}_{3}\right)_{2} \cdot 24 \mathrm{H}_{2} \mathrm{O}(2) \cdot \mathrm{H}_{2} \mathrm{~L}(1 \mathrm{ml}$, $0.1 \mathrm{mmol}), \mathrm{Tb}\left(\mathrm{NO}_{3}\right)_{3} \cdot 5 \mathrm{H}_{2} \mathrm{O}(0.0435 \mathrm{~g}, 0.1 \mathrm{mmol}), \mathrm{Ni}\left(\mathrm{CH}_{3} \mathrm{COO}\right)_{2} \cdot 4 \mathrm{H}_{2} \mathrm{O}$ $(0.0260 \mathrm{~g}, 0.1 \mathrm{mmol})$ and $\mathrm{LiOH}(0.0840 \mathrm{~g}, 0.2 \mathrm{mmol})$. Yield: $0.041 \mathrm{~g} .68 \%$ based on Tb. Anal. Calcd for $\mathrm{C}_{60} \mathrm{H}_{134} \mathrm{~Tb}_{4} \mathrm{Ni}_{4} \mathrm{~N}_{6} \mathrm{O}_{64}$ (2834.19) C, 25.43; H, 4.77; N, 2.97. Found: C, 25.19; H, 4.81; N; 2.89. Selected FT-IR peaks $(\mathrm{KBr}, \mathrm{cm}-1 ; \mathrm{s}=$ strong, $\mathrm{vs}=$ very strong, $\mathrm{m}=$ medium, $\mathrm{br}=$ broad $): 3415$ (br), $1654(\mathrm{~m}), 1607(\mathrm{~s}), 1567(\mathrm{~s}), 1465(\mathrm{~m}), 1417$ (vs), $1342(\mathrm{~s}), 1266(\mathrm{~m})$, $1243(\mathrm{~m}), 1225(\mathrm{~m}), 1080(\mathrm{~m}), 1036(\mathrm{~m}), 969(\mathrm{w}), 850(\mathrm{w}), 750(\mathrm{~m}), 736$ $(\mathrm{m}), 644(\mathrm{~m})$. UV-vis spectra in MeOH: $\lambda \max , \mathrm{nm}\left(\varepsilon, \mathrm{L} \mathrm{mol}_{-1} \mathrm{~cm}_{-1}\right)=603$ (2822), 371 (14886), 277 (30626), 233 (88420), 207 (72319).

$\left[\mathrm{Ni}_{4} \mathrm{Dy}_{4}(\mathrm{HL})_{4}\left(\mu_{2}-\mathrm{OH}\right)_{2}\left(\mu_{3}-\mathrm{OH}\right)_{4}\left(\mu-\mathrm{OOCCH}_{3}\right)_{8}\right] \cdot\left(\mathrm{NO}_{3}\right)_{2} \cdot \mathbf{1 7 H}_{2} \mathrm{O}(3) . \mathrm{H}_{2} \mathrm{~L}(1 \mathrm{ml}$, $0.1 \mathrm{mmol}), \operatorname{Dy}\left(\mathrm{NO}_{3}\right)_{3} \cdot 5 \mathrm{H}_{2} \mathrm{O}(0.0438 \mathrm{~g}, 0.1 \mathrm{mmol}), \mathrm{Ni}\left(\mathrm{CH}_{3} \mathrm{COO}\right)_{2} \cdot 4 \mathrm{H}_{2} \mathrm{O}$ $(0.0260 \mathrm{~g}, 0.1 \mathrm{mmol})$ and $\mathrm{LiOH}(0.0840 \mathrm{~g}, 0.2 \mathrm{mmol})$. Yield: $0.038 \mathrm{~g} ; 63 \%$ based on Dy. Anal. Calcd for $\mathrm{C}_{60} \mathrm{H}_{120} \mathrm{Dy} 4 \mathrm{Ni}_{4} \mathrm{~N}_{6} \mathrm{O}_{57}$ (2722.38 g): C, 26.47 ; 
$\mathrm{H}, 4.44 ; \mathrm{N}, 3.09$. Found: $\mathrm{C}, 26.29 ; \mathrm{H}, 4.28, \mathrm{~N}, 2.93$. Selected FT-IR peaks $(\mathrm{KBr}, \mathrm{cm}-1 ; \mathrm{s}=$ strong, $\mathrm{vs}=$ very strong, $\mathrm{m}=$ medium, $\mathrm{br}=$ broad $): 3417$ (br), $1654(\mathrm{~m}), 1615$ (s), 1569 (s), $1467(\mathrm{~m}), 1424$ (vs), 1335 (s), 1266 (s), $1243(\mathrm{~m}), 1227(\mathrm{~m}), 1082(\mathrm{~m}), 1036(\mathrm{~m}), 973(\mathrm{~m}), 736(\mathrm{~m}), 644(\mathrm{~m})$. UV vis spectra in $\mathrm{MeOH}: \lambda_{\max }, \mathrm{nm}\left(\varepsilon, \mathrm{L} \mathrm{mol}_{-1} \mathrm{~cm}_{-1}\right)=603$ (2797), $372(14330)$, 278 (29365), 234 (84305), 206 (63638).

$\left[\mathrm{Ni}_{4} \mathrm{Ho}_{4}(\mathrm{HL})_{4}\left(\mu_{2}-\mathrm{OH}\right)_{2}\left(\mu_{3}-\mathrm{OH}\right)_{4}\left(\mu-\mathrm{OOCCH}_{3}\right)_{8}\right] \cdot\left(\mathrm{NO}_{3}\right)_{2} \cdot 19 \mathrm{H}_{2} \mathrm{O}(4) . \mathrm{H}_{2} \mathrm{~L}(1 \mathrm{ml}$, $0.1 \mathrm{mmol}), \mathrm{Ho}\left(\mathrm{NO}_{3}\right)_{3} \cdot 5 \mathrm{H}_{2} \mathrm{O}(0.0441 \mathrm{~g}, 0.1 \mathrm{mmol}), \mathrm{Ni}\left(\mathrm{CH}_{3} \mathrm{COO}\right)_{2} \cdot 4 \mathrm{H}_{2} \mathrm{O}$ $(0.0260 \mathrm{~g}, 0.1 \mathrm{mmol})$ and $\mathrm{LiOH}(0.0840 \mathrm{~g}, 0.2 \mathrm{mmol})$. Yield: $0.041 \mathrm{~g} ; 67 \%$

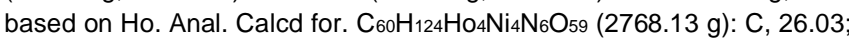
$\mathrm{H}, 4.52 ; \mathrm{N}, 3.04$. Found: $\mathrm{C}, 25.82 ; \mathrm{H}, 4.45 ; \mathrm{N}, 3.11$. Selected FT-IR peaks $(\mathrm{KBr}, \mathrm{cm}-1 ; \mathrm{s}=$ strong, $\mathrm{vs}=$ very strong, $\mathrm{m}=$ medium, $\mathrm{br}=$ broad $): 3415(\mathrm{br})$, $1654(\mathrm{~s}), 1614(\mathrm{~m}), 1567(\mathrm{~m}), 1464(\mathrm{~m}), 1416(\mathrm{vs}), 1336(\mathrm{~s}), 1266(\mathrm{~s}), 1243$ $(\mathrm{m}), 1224(\mathrm{~m}), 1079(\mathrm{~m}), 1034(\mathrm{~m}), 968(\mathrm{~m}), 737(\mathrm{~m}), 644(\mathrm{~m})$. UV-vis spectra in MeOH: $\lambda_{\max }, \mathrm{nm}\left(\varepsilon, \mathrm{L} \mathrm{mol}_{-1} \mathrm{~cm}_{-1}\right)=581$ (4265), 373 (14421), 278 (30191), 233 (86648), 206 (67168).

$\left[\mathrm{Ni}_{4} \mathrm{Yb}_{4}(\mathrm{HL})_{4}\left(\mu_{2}-\mathrm{OH}\right)_{2}\left(\mu_{3}-\mathrm{OH}\right)_{4}\left(\mu-\mathrm{OOCCH}_{3}\right)_{8}\right] \cdot\left(\mathrm{NO}_{3}\right)_{2} \cdot 24 \mathrm{H}_{2} \mathrm{O}(5) . \mathrm{H}_{2} \mathrm{~L}(1 \mathrm{ml}$, $0.1 \mathrm{mmol}), \mathrm{Yb}\left(\mathrm{NO}_{3}\right)_{3} \cdot 6 \mathrm{H}_{2} \mathrm{O}(0.0383 \mathrm{~g}, 0.1 \mathrm{mmol}), \mathrm{Ni}\left(\mathrm{CH}_{3} \mathrm{COO}\right)_{2} \cdot 4 \mathrm{H}_{2} \mathrm{O}$ $(0.0260 \mathrm{~g}, 0.1 \mathrm{mmol})$ and $\mathrm{LiOH}(0.0840 \mathrm{~g}, 0.2 \mathrm{mmol})$. Yield: $0.042 \mathrm{~g} .68 \%$ based on Yb. Anal. Calcd for. $\mathrm{C}_{60} \mathrm{H}_{134} \mathrm{Yb}_{4} \mathrm{Ni}_{4} \mathrm{~N}_{6} \mathrm{O}_{64}(2890.70 \mathrm{~g})$ : C, 24.93 ; $\mathrm{H}, 4.67 ; \mathrm{N}, 2.91$. Found: C, 24.73; H, 4.45; N, 2.74. Selected FT-IR peaks $(\mathrm{KBr}, \mathrm{cm}-1 ; \mathrm{s}=$ strong, $\mathrm{vs}=$ very strong, $\mathrm{m}=$ medium, $\mathrm{br}=$ broad $): 3362$ (br), $1655(\mathrm{~s}), 1608(\mathrm{~m}), 1560(\mathrm{vs}), 1467(\mathrm{~m}), 1411(\mathrm{vs}), 1332(\mathrm{~s}), 1266$ (s), $1243(\mathrm{~m}), 1223(\mathrm{~m}), 1072(\mathrm{~m}), 1036(\mathrm{~m}), 963(\mathrm{~m}), 737(\mathrm{~m}), 648(\mathrm{~m})$. UVvis spectra in $\mathrm{MeOH}: \lambda_{\max }, \mathrm{nm}\left(\varepsilon, \mathrm{L} \mathrm{mol}_{-1} \mathrm{~cm}-1\right)=603$ (1702), 372 (13757), 278 (29541), 233 (82353), 207 (61531).

Physical measurements. Elemental analyses $(\mathrm{C}, \mathrm{H}, \mathrm{N})$ of the complexes were performed on PerkinElmer model $240 \mathrm{C}$ elemental analyzer. FT-IR (ATR) spectra were recorded on a PerkinElmer Spectrum Two Spectrometer. Solution phase electronic absorption spectra were recorded using a Shimadzu UV 3100 UV-vis-NIR spectrophotometer. HRMS were recorded in electrospray ionization (ESI) mode using a Bruker esquire 3000 plus mass spectrometer. The solid state diffuse reflectance spectra (DRS) were measured using a Cary model 5000 UV-vis-NIR spectrophotometer. The powder X-ray diffraction (PXRD) patterns were measured on Bruker AXS X-ray diffractrometer using $\mathrm{Cu}$ - $\mathrm{Ka}(\lambda=1.5418$ $\AA$ ) radiation source within the angular range of $(2 \theta) 5-50^{\circ}$ and a fixed-time counting of $4 \mathrm{~s}$ at $25^{\circ} \mathrm{C}$.

Magnetic measurements. Magnetic susceptibility measurements of polycrystalline complexes 1-5 were performed using quantum Design SQUID MPMS-XL magnetometer equipped with a $5 \mathrm{~T}$ magnet in the Unitat de Mesures Magnètiques (Universitat de Barcelona). The dc magnetic susceptibility was measured in the temperature range of $2-300 \mathrm{~K}$ using the applied magnetic field of 3000 Oe and below $30 \mathrm{~K}$ of 198 Oe. Fielddependent magnetization measurements were performed at $2 \mathrm{~K}$, under the field of $0-5 \mathrm{~T}$. The experimental magnetic data were corrected for the diamagnetism of sample holder and diamagnetic corrections were calculated using Pascal's constants.

X-ray crystallographic measurements. The crystallographic data of the complexes 1-5 were measured on Bruker SMART APEX-II CCD X-ray diffractometer, equipped with a graphite monochromator of Mo-Ka radiation $(\lambda=0.71073 \AA$ ) source. Measurements were performed by using $\omega$ scan method at 180-197 $\mathrm{K}$ temperature. The software SAINT 32 and $\mathrm{XPREP}_{33}$ were used for data integration and space group determination. The structures were solved by direct method of SHELXT-201434 and refined with full-matrix least squares on $\mathrm{F}_{2}$ using the SHELXL 35 program package associated with the Olex-2 software. 36 The software SADABS 37 was employed to the data for the absorption correction. The position of heavier atoms $(\mathrm{Ni}, \mathrm{Ln})$ were determined easily, and positions of $\mathrm{C}, \mathrm{N}, \mathrm{O}$ were subsequently determined from difference Fourier maps. The atoms were refined anisotropically. The $\mathrm{H}$ atoms were placed in calculated positions and refined with fixed geometry and riding thermal parameters with respect to their carrier atoms. The crystallographic diagrams were generated using DIAMOND 38 and POV-ray 39 software. All the complexes 1-5 contain solvent molecules of large thermal parameter and could not be modelled satisfactorily. Hence the solvent molecules were removed by using PLATON/squeeze40 program which generated an electron count of $106,440,156,175$ and 452 for complexes $1-5$ respectively were assigned for the $10,22,15,17$ and $22 \mathrm{H}_{2} \mathrm{O}$ molecules. The information of crystal structures $\mathbf{1 - 5}$ and relevant structure refinement parameters are summarized in Table 1.

\section{Acknowledgements}

M.B. is thankful to the University Grants Commission (UGC) New Delhi, India for financial support. We thank the DST, New Delhi, India, for providing the single-crystal X-ray diffractometer facility at the Department of Chemistry, IIT Kharagpur, under its FIST program. ECS acknowledges the financial support from the Spanish Government (Grant CTQ2015-68370-P).

Keywords: coordination aggregates $(\mathrm{CAs}) \cdot$ single molecule magnets $(\mathrm{SMMs}) \cdot$ crystal structure $\bullet$ coordination environment $•$ anisotropy

[1] (a) T. Lis, Acta Cryst. 1980, B 36, 2042-2046. (b) D. N. Hendrickson, G. Christou, D. Gatteschi, K. Foiling, J. B. Vincent, S. Wang, A. R. Schake, H.-L. Tsai, R. Sessoli, J. Am. Chem. Soc. 1993, 115, 1804-1816.

[2] (a) C. J. Milios, A. Vinslava, W. Wernsdorfer, S. Moggach, S. Parsons, S. P. Perlepes, G. Christou, E. K. Brechin, J. Am. Chem. Soc. 2007, 129, 2754-2755. (b) A. Bencini, C. Benelli, A. Caneschi, R. L. Carlin, A. Dei, D. Gatteschi, J. Am. Chem. Soc. 1985, 107, 8128-8136. (c) C. Papatriantafyllopoulou, W. Wernsdorfer, K. A. Abboud, G. Christou, Inorg. Chem. 2011, 50, 421-423. (d) F. Habib, P.-H. Lin, J. Long, I. Korobkov, W. Wernsdorfer, M. Murugesu, J. Am. Chem. Soc. 2011, 133, 8830-8833;

[3] (a) J. D. Rinehart, J. R. Long, J. Am. Chem. Soc. 2009, 131, 1255812559. (b) A. Ardavan, S. J. Blundell, J. Mater. Chem. 2009, 19, 17541760.

[4] (a) L. Bogani, W. Wernsdorfer, Nat. Mater. 2008, 7, 179-186. (b) A. R Rocha, V. M. García-suárez, S. W. Bailey, C. J. Lambert, J. Ferrer, S. Sanvito, Nat. Mater. 2005, 4, 335-339.

[5] (a) D. Gatteschi, A. Caneschi, L. Pardi, R. Sessoli, Science. 1994 265,1054-1058. (b) A. Ardavan, O. Rival, J. J. L. Morton, S. J. Blundell, Phys. Rev. Lett. 2007, 98, 057201-4. (c) J. Liu, Y.-C. Chen, J.-L. Liu, V. Vieru, L. Ungur, J.-H. Jia, L. F. Chibotaru, Y. Lan, W. Wernsdorfer, S. Gao, X.-M. Chen, M.-L. Tong, J. Am. Chem. Soc. 2016, 138, 5441-5450.

[6] (a) M. Murrie, S. J. Teat, H. Stœckli-Evans, H. U. Gudel, Angew. Chem Int. Ed. 2003, 42, 4653 -4656. (b) A. K. Mondal, S. Khatua, K. Tomar, S. Konar, Eur. J. Inorg. Chem. 2016, 2016, 3545-3552. (c) C. Cadiou, M. Murrie, C. Paulsen, V. Villar, W. Wernsdorfer, R. E. P. Winpenny, Chem. Commun. 2001, 24, 2666-2667.

[7] (a) L. R. Rosado Piquer, E. C. Saňudo, Dalton Trans. 2015, 44 8771-8780. (b) J. W. Sharples, D. Collison, Coord. Chem. Rev. 2014, 260, 1-20.

[8] (a) D. N. Woodruf, R. E. P. Winpenny, R. A. Layfield, Chem. Rev. 2013, 113, 5110-5148. (b) J. Tang, I. Hewitt, N. T. Madhu, G. Chastanet, W. Wernsdorfer, C. E. Anson, C. Benelli, R. Sessoli, A. K. Powell, Angew.Chem., Int. Ed., 2006, 45, 1729-1733. (c) S.-D. Jiang, B.-W. Wang, G. Su, Z.-M. Wang, S. Gao, Angew. Chem. 2010, 122, $7610-$ 7613

[9] (a) M. Murugesu, L. F. Chibotaru, W. Wernsdorfer, L. Ungur, G. Enright I. Korobkov, P.-H. Lin, F. Habib, J. Long, J. Am. Chem. Soc. 2011, 133, 5319-5328. (b) M. Chen, E. C. Sañudo, E. Jimenez, S.-M. Fang, C.-S. Liu, M. Du, Inorg. Chem. 2014, 53, 6708-6714. (c) J. Tang, L. Zhao, J. Wu, M. Guo, X.-L. Li, Y,-Q. Zhang, J. Lu, Inorg. Chem. 2019, 58, 5715-5724 
[10] (a) F.-S. Guo, B. M. Day, Y.-C. Chen, M.-L. Tong, A. Mansikkamaki, R. A. Layfield, Science 2018, 362, 1400-1403. (b) C. A. P. Goodwin, F. Ortu D. Reta, N. F. Chilton, D. P. Mills, Nature 2017, 548, 439-442. (c) F. S. Guo, B. M. Day, Y. C. Chen, M. L Tong, A. Mansikkamäki, R. A. Layfield, Angew. Chem. Int. Ed. 2017, 56, 11445-11449.

[11] (a) Y.-N. Guo, G.-F. Xu, W. Wernsdorfer, L. Ungur, Y. Guo, J. Tang, H.J. Zhang, L. F. Chibotaru, A. K. Powell, J. Am. Chem. Soc. 2011, 133 11948-11951. (b) R. Sessoli, A. K. Powell, Coord. Chem. Rev. 2009 253, 2328-2341.

[12] (a) K. S. Murray, L. F. Chibotaru, B. Moubaraki, L. Ungur, N. F. Chilton, S. K. Langley, Inorg. Chem. 2012, 51, 11873-11881. (b) Z.-Q. Pan, Y. Q. Zhang, Z.-C. Zhang, Y. Song, J. Li, H.-S. Wang, Q.-Q. Long, Z.-B. Hu, C.-L. Yin, Dalton Trans. 2019, 48, 512-522. (c) G. Rajaraman, K. S Murray, S. K. Langley, K. R. Vignesh, Inorg. Chem. 2017, 56, 2518-2532.

[13] (a) M. Holynska, D. Premuzic, I.-R. Jeon, W. Wernsdorfer, R. Clerac, S. Dehnen, Chem.-Eur. J. 2011, 17, 9605 - 9610. (b) T. C. Stamatatos, S. J. Teat, W. Wernsdorfer, G. Christou, Angew. Chem. Int. Ed. 2009, 48 521 -524. (c) J. Rinck, G. Novitchi, W. V. Heuvel, L. Ungur, Y. Lan, W. Wernsdorfer, C. E. Anson, L. F. Chibotaru, A. K. Powell, Angew. Chem. Int. Ed. 2010, 49, $7583-7587$.

[14] (a) M.-X. Yao, Z.-X. Zhu, X.-Y. Lu, X.-W. Deng, S. Jing, Dalton Trans. 2016, 45, 10689-10695. (b) N. Ahmed, C. Das, S. Vaidya, S. K. Langley, K. S. Murray, M. Shanmugam, Chem. Eur. J. 2014, 20, 14235 - 14239. (c) P. Kalita, J. Goura, J. M. Herrera, E. Colacio, V. Chandrasekhar, ACS Omega. 2018, 3, 5202-5211. (d) L. Rosado Piquer, E. J. Romero, Y. Lan W. Wernsdorfer, G. Aromi, E. C. Sañudo, Inorg. Chem. Front. 2017, 4 595-603.

[15] (a) J.-B. Peng, Q.-C. Zhang, X.-J. Kong, Y.-Z. Zheng, Y.-P. Ren, L.-S. Long, R.-B. Huang, L.-S. Zheng, Z. Zheng, J. Am. Chem. Soc. 2012, 134 3314-3317. (b) F. Shao, J.-J. Zhuang, M.-G. Chen, N. Wang, H.-Y. Shi, J.-P. Tong, G. Luo, J. Tao, L.-S. Zheng, Dalton Trans. 2018, 47, 16850 16854. (c) E. Guarda, K. Bader, J. V. Slageren, P. Alborés, Dalton Trans. 2016, 45, 8566-8572.

[16] (a) X. Yang, Z. Li, S. Wang, S. Huang, D. Schipper, R. A. Jones, Chem. Commun. 2014, 50,15569-15572. (b) S. K. Langley, D. P. Wielechowski, V. Vieru, N. F. Chilton, B. Moubaraki, B. F. Abrahams, L. F. Chibotaru, K. S. Murray, Angew. Chem. Int. Ed. 2013, 52, 12014 -12019. (c) F Evangelisti, R. More, F. Hodel, S. Luber, G. R. Patzke, J. Am. Chem. Soc. 2015, 137, 11076-11084. (d) G. Maayan, G. Christou, Inorg. Chem. 2011, 50, 7015-7021.

[17] (a) P. Wang, S. Shannigrahi, N. L. Yakovlev, T. S. A. Hor, Chem. Asian J. 2013, 8, 2943-2946. (b) Z.-S. Meng, F.-S. Guo, J.-L. Liu, J.-D. Leng, M.-L. Tong, Dalton Trans. 2012, 41, 2320-2329.

[18] (a) A. Sieber, C. Boskovic, R. Bircher, O. Waldmann, S. T. Ochsenbein, G. Chaboussant, H. U. Gudel, N. Kirchner, J. V. Slageren, W. Wernsdorfer, A. Neels, H. Stoeckli-Evans, S. Janssen, F. Juranyi, H. Mutka, Inorg. Chem. 2005, 44, 4315-4325; (b) X. Qin, S. Ding, X. Xu, R. Wang, Y. Song, Y. Wang, C.-f. Du, Z.-I. Liu, Polyhedron 2014, 83, 3643.

[19] Y. Gao, L. Zhao, X. Xu, G.-F. Xu, Y.-N. Guo, J. Tang, Z. Liu, Inorg. Chem. 2011, 50, 1304-1308.

[20] P. Wang, S. Shannigrahi, N. L. Yakovlev, T. S. A. Hor, Dalton Trans 2014, 43, 182-187.

[21] M. Llunell, D. Casanova, J. Cirera, J. M. Bofill, P. Alemany, S. Alvarez, M. Pinsky, D. Avnir, SHAPE (2.1); Universitat de Barcelona: Barcelona, Spain, 2013

[22] M. Pait, A. Bauzá, A. Frontera, E. Colacio, D. Ray, Inorg. Chem. 2015 54, 4709-4723.

[23] (a) M. A. Halcrow, J.-S. Sun, J. C. Huffman, G. Christou, Inorg. Chem. 1995, 34, 4167-4177. (b) K. Isele, F. Gigon, A. F. Williams, G. Bernardinelli, P. Franz, S. Decurtins, Dalt. Trans. 2007, 332-341.
[24] (a) M. Andruh, J.-P. Costes, C. Diaz, S. Gao, Inorg. Chem. 2009, 48 3342-3359. (b) L. Zhao, J. Wu, H. Ke, J. Tang, Inorg. Chem. 2014, 53, 3519-3525. (c) H. Ke, L. Zhao, Y. Guo, J. Tang, Inorg. Chem (Washington, DC, United States) 2012, 51, 2699-2705.

[25] N. F. Chilton, R. P. Anderson, L. D. Turner, A. Soncini, K. S. Murray, J. Comput. Chem. 2013, 34, 1164-1175.

[26] M. Biswas, E. C. Sañudo, J. Cirera, D. Ray, New J. Chem. 2020, 44, 4812-4821.

[27] L. Rosado Piquer, S. Dey, L. Castilla-Amorós, S. J. Teat, J. Cirera, G. Rajaraman, E. C. Sañudo, Dalton Trans. 2019, 48, 12440-12450.

[28] N. F. Chilton, D. Collison, E. J. L. Mclnnes, R. E. P. Winpenny, A. Soncini, Nat. Commun. 2013, 4, 2551-2557.

[29] J. D. Rinehart, J. R. Long, Chem. Sci. 2011, 2, 2078-2085.

[30] S. G. Dogaheh, H. Khanmohammadi, E. C. Sañudo, New J. Chem. 2017, 41, 10101-10111

[31] L. Yan, S. Ding, Y. Ji, Z. Liu, C. Liu, J. Coord. Chem. 2011, 64, 35313540 .

[32] SAINT Plus, Version 7.03; Bruker AXS Inc.: Madison, WI, 2004.

[33] Smart and XPREP; Siemens Analytical X-ray Instruments Inc., Madison, WI, 1995.

[34] G. M. Sheldrick, SHELXT-Integrated Space-Group and CrystalStructure Determination. Acta Crystallogr., Sect. A: Found. Adv., 2015, 71, 3-8

[35] G. M. Sheldrick, Crystal Structure Refinement with SHELXL. Acta Crystallogr., Sect. C: Struct. Chem. 2015, 71, 3-8

[36] O. V. Dolomanov, L. J. Bourhis, R. J. Gildea, J. A. K. Howard and H. Puschmann, J. Appl. Crystallogr. 2009, 42, 339-341.

[37] G. M. Sheldrick, SADABS: Software for empirical absorption correction Ver. 2.05; University of Göttingen: Göttingen, Germany, 2002.

[38] K. Bradenburg, DIAMOND, version 3.1; Crystal Impact, Bonn, Germany, 2004

[39] L. J. Farrugia, POV-Ray - 3.5; University of Glasgow, Glasgow, U.K., 2003

[40] A. L. Spek, Acta Crystallogr., Sect. C: Struct. Chem., 2015, 71, 9-18. 